LEVERAGING MATH COGNITION

\title{
Leveraging Math Cognition to Combat Health Innumeracy
}

Clarissa A. Thompson ${ }^{1}$, Marta K. Mielicki ${ }^{1}$, Ferdinand Rivera ${ }^{2}$, Charles J. Fitzsimmons ${ }^{1}$, Daniel A. Scheibe ${ }^{1}$, Pooja G. Sidney ${ }^{3}$, Jennifer M. Taber ${ }^{1}$, and Erika A. Waters ${ }^{4}$

\author{
${ }^{1}$ Kent State University \\ ${ }^{2}$ San Jose State University \\ ${ }^{3}$ University of Kentucky \\ ${ }^{4}$ Washington University School of Medicine in St. Louis
}

Corresponding Author

Clarissa A. Thompson

Associate Professor of Psychological Sciences

Kent State University

P.O. Box 5190

228 Kent Hall Addition

Kent, OH 44242

330-672-3948

cthomp77@kent.edu

www.clarissathompson.com

\section{Acknowledgments}

The authors would like to thank Julie Nurnberger-Haag for early discussions about this paper. The writing of this paper was supported in part by U.S. Department of Education, Institute of Education Sciences Grant \# R305A160295 and R305U200004.

The authors have no conflicts of interest to declare.

Note: This paper is currently accepted at Perspectives on Psychological Science. 


\title{
LEVERAGING MATH COGNITION
}

\author{
Abstract \\ Rational numbers (i.e., fractions, percentages, decimals, and whole-number frequencies) are \\ notoriously difficult mathematical constructs. Yet, correctly interpreting rational numbers is \\ imperative for understanding health statistics, such as gauging the likelihood of side effects from \\ a medication. Several pernicious biases impact health decision making involving rational \\ numbers. In our novel developmental framework, the natural number bias--a tendency to \\ misapply knowledge about natural numbers to all numbers--is the mechanism underlying other \\ biases that shape health decision making. Natural number bias occurs when people \\ automatically process natural-number magnitudes and disregard ratio magnitudes. Math \\ cognition researchers have identified individual differences and environmental factors underlying \\ natural number bias and devised ways to teach people how to avoid these biases. Although \\ effective interventions from other areas of research can help adults evaluate numerical health \\ information, they circumvent the core issue: people's penchant to automatically process natural \\ number magnitudes and disregard ratio magnitudes. We describe the origins of natural number \\ bias and how researchers may harness the bias to improve rational number understanding and \\ ameliorate innumeracy in real-world contexts, including health. We recommend modifications to \\ formal math education to help children learn the connections among natural and rational \\ numbers. Additionally, we call on researchers to consider individual differences people bring to \\ health decision-making contexts, and how measures from math cognition might identify those \\ who would benefit most from support when interpreting health statistics. Investigating \\ innumeracy with an interdisciplinary lens could advance understanding of innumeracy in \\ theoretically meaningful and practical ways.
}




\section{LEVERAGING MATH COGNITION}

Keywords: math cognition, decision making, natural number bias, ratio bias, denominator neglect, 1-in-x phenomenon, interdisciplinary collaborations 
LEVERAGING MATH COGNITION

\section{Leveraging Math Cognition to Combat Health Innumeracy}

Adults are frequently inundated with statistics in the form of rational numbers, such as fractions (e.g., 1/4), percentages (e.g., 25\%), decimals (e.g., 0.25), and whole number frequencies (e.g., 25 out of 100). For instance, a woman may be presented with the statistic that 1 in 8 women experience breast cancer in their lifetime and may rely on this information when deciding whether to schedule diagnostic screenings. How does she interpret this statistic? What numerical factors might influence her understanding of this breast-cancer risk? If she were to compare this risk to that of heart disease, which impacts 1 in 4 people in the U.S., would she consider this to be a lower or higher health risk? Perhaps she, like many other people, would overestimate her risk of cancer relative to heart disease (Scheideler et al., 2017).

A myriad of factors influence the decisions people make about their own or others' health. In this paper, we focus on one critical aspect of many health decisions -(mis)interpretation of numerical health statistics that results from knowledge about, and experiences with, rational numbers. This is an important focus because this (mis)interpretation is malleable and can be improved via intervention. We outline the pernicious biases that impact people's ability to reason with numerical health information. For example, people often neglect denominators and only attend to numerators when comparing health statistics like 4 in 10,000 vs. 3 in 1,000, and, in doing so, reach the mistaken conclusion that 4 in 10,000 is the larger of the two risks, even though it is smaller in magnitude than 3 in 1,000. In one real-world example, consumers believed they were getting less value for their money for A\&W's third-pound burger than McDonald's Quarter Pounder because 3 is smaller than 4 (Conradt, 2016). This phenomenon, in which people attend only to one of two quantities in a ratio (a:b), or only to the numerator or denominator in a fraction in isolation, is known by different terms: ratio bias

(Bourdin et al., 2021), 1-in-x phenomenon, or denominator neglect in the health cognition 


\section{LEVERAGING MATH COGNITION}

literature and natural number bias or whole number bias in the domain of math cognition (see glossary below).

Researchers in the decision-making literature have developed communication strategies to help adults reason with numerical health information (e.g., Bonner et al., 2021; Lipkus, 2007; Nelson et al., 2008; Waters et al., 2016; 2021; Zikmund-Fisher, 2011). However, these strategies do not necessarily address the root of the numerical biases that impede informed decision-making. Moreover, these biases are not limited to the health domain, but occur in scholastic (e.g., Ni \& Zhou, 2005), financial (Peters et al., 2019; Sobkow et al., 2019), and presumably any other context in which rational numbers are involved. These biases are all instances of a more general cognitive bias that results from the tendency to misapply knowledge about natural numbers to all other numbers (e.g., even though $4>3,3 / 1,000>4 / 10,000$; Siegler et al., 2011). As mentioned above, this tendency is known as the natural number bias in the domain of math cognition, and it arises from constraints on the human perceptual system, statistical regularities in the environment (i.e., prevalence of natural numbers in everyday life), and difficulties with rational number understanding that stem from formal classroom lessons (Moss \& Case, 1999). Figure 1 illustrates our novel developmental framework, which we describe in subsequent sections, including the antecedents of natural number bias and its downstream consequences. The two thick gray arrows in Figure 1 are expanded in Figure 2 and illustrate the inflection points where interventions can occur (i.e., in childhood or during adulthood) to dampen the effects of the natural number bias.

\section{Figure 1}

A Novel Developmental Framework for Identifying the Antecedents and Downstream Consequences of the Natural Number Bias 


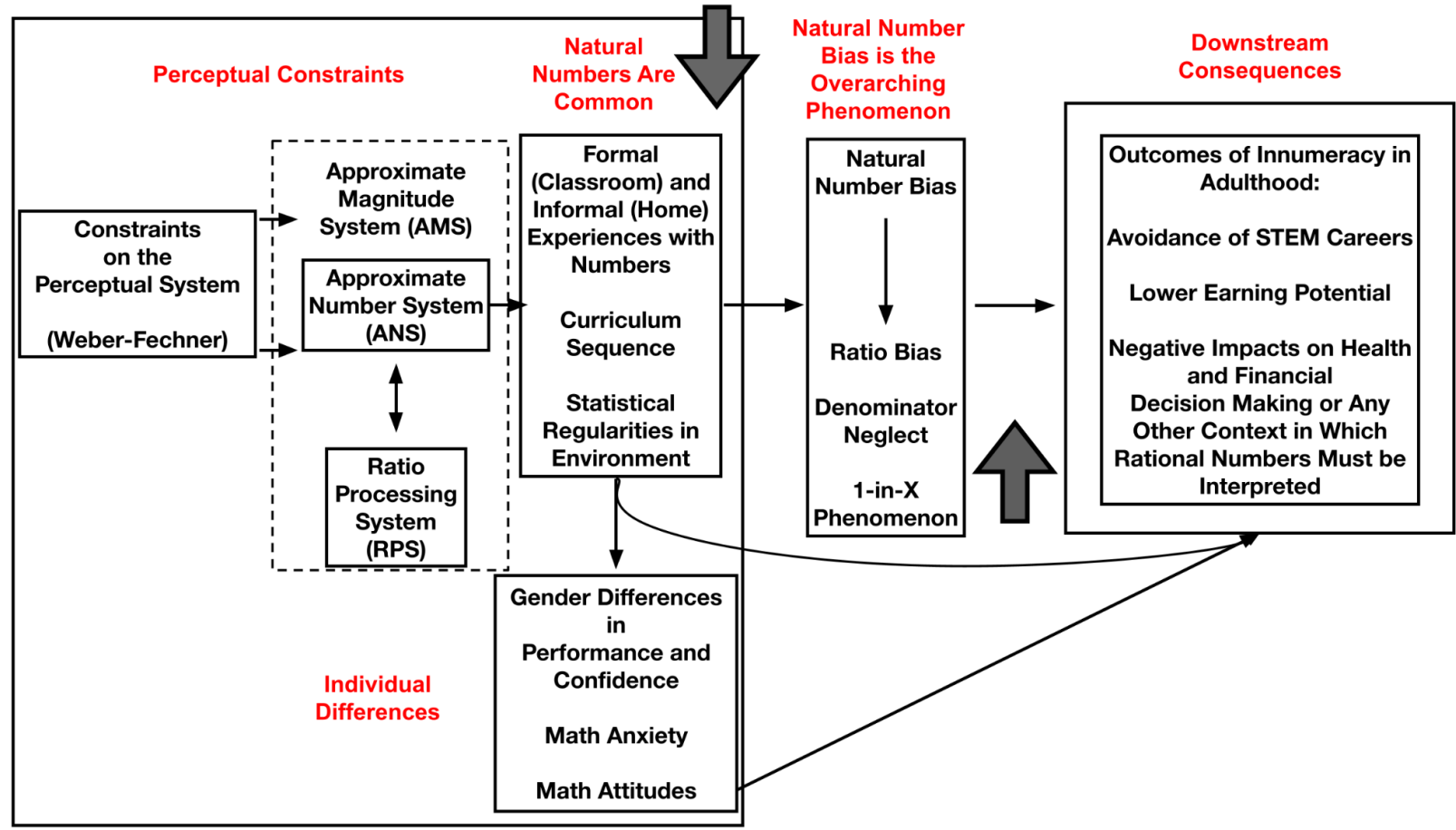

Note. Each section of the figure is discussed in detail in the text. The thick gray arrows are inflection points where interventions can occur (i.e., in childhood or during adulthood) to dampen the effects of the natural number bias. Note that there are downstream consequences of the natural number bias in any situation in which people must interpret rational numbers.

\section{Figure 2}

Inflection Points for Interventions to Override Natural Number Bias 


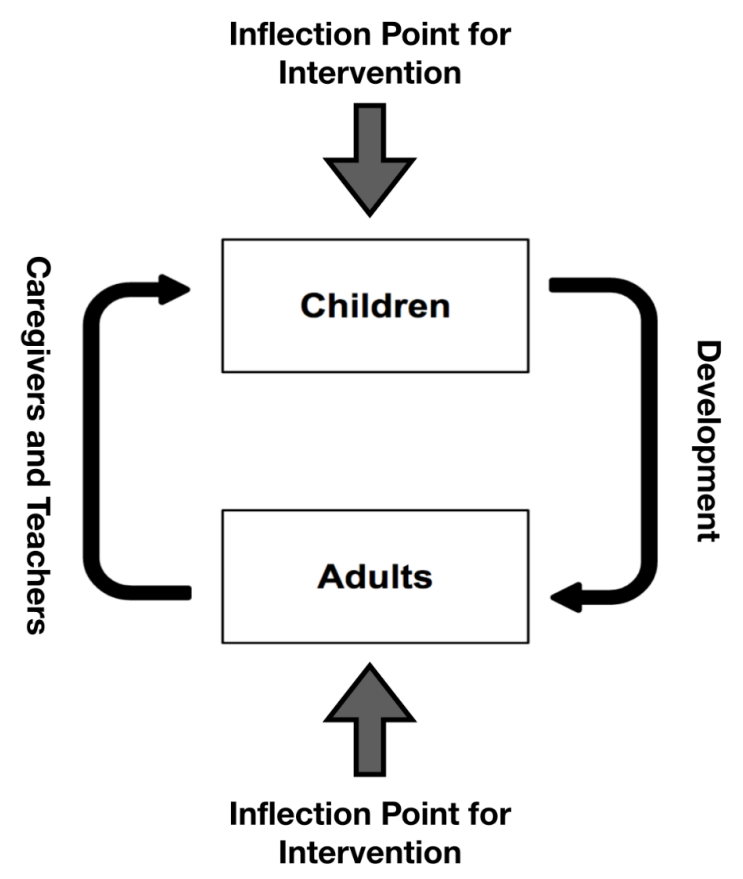

Note. If we intervene on adults, they could help children combat natural number bias as parents and teachers. If we intervene on children, they will become adults who are less likely to fall prey to the natural number bias.

In the current paper, we explicate the benefits of integrating theoretical and methodological insights from the fields of both math cognition and health decision making. Prior reviews of numeracy in the domain of health decision making have emphasized different theoretical perspectives that may account for innumeracy, including some from cognitive perspectives (Lipkus \& Peters, 2010; Peters, 2020; Peters \& Bjalkebring, 2015; Reyna, 2008; Reyna \& Brainerd, 2007; see section 3a below). In her recently released book, Innumeracy in the Wild, Ellen Peters (2020) describes various mathematical and non-mathematical factors that impact health and financial decision making. She asserts,

"Our grasp of numbers and uncertainty is one of humankind's most distinctive and important traits. It is pivotal to our exceptional ability to control the world around us as we make short-term choices and forecast far into the future. But, very smart people can struggle with numbers in ways that pose negative consequences for their decision 


\section{LEVERAGING MATH COGNITION}

making. Numeric ability equips individuals with vital tools that allow them to take charge of various aspects of their life. The more numerate enjoy superior health, wealth, and employment outcomes, while the innumerate remain more vulnerable."

One overarching goal within the domain of numeracy and decision making is to find ways to make the innumerate less vulnerable to adverse health outcomes. We propose that this can be done at least in part through developing and implementing interventions that help individuals think more deeply about the magnitude of rational numbers, which should in turn decrease the likelihood of automatically processing ratios in a biased way. This paper is intended to inform efforts to advance this overarching goal of promoting positive health outcomes.

In addition, we propose that our own recent cross-disciplinary efforts have shown promise in integrating theoretical and methodological insights from both math cognition and health decision making (Choi et al., 2020; Mielicki et al., invited revision; Scheibe et al., invited revision under review; Thompson, Taber, et al., 2021; Thompson, et al., in press; Woodbury et al., invited revision). We believe that interdisciplinary, collaborative science that bridges domains has the potential to make the greatest real-world impact (Klein et al., 2017). Psychology is a "hub science" with strong connections to many other disciplines (Cacioppo, 2007). Similar to other "calls to action" which have urged researchers to clarify terminology and measurement tools to move fields forward (Norton \& Nurnberger-Haag, 2018; Rittle-Johnson, 2017), a collaborative approach among scientists who identify as cognitive, developmental, social, and health psychologists, math education researchers, and judgment and decision-making researchers is critical to meeting the goal of helping adults appropriately interpret the numerical information inherent in health statistics. It is very difficult for any one researcher to stay completely abreast of nuances in multiple literatures, especially when the same constructs are 


\section{LEVERAGING MATH COGNITION}

referred to with different terminology (see glossary). By taking a "team science" approach, (Hall

et al., 2018; National Research Council, 2015) in which we examine the research problem

through various research lenses, we can create and test multifaceted solutions that may be

more impactful than those produced from any one discipline alone.

In the next sections, we provide an overview of (a) the far-reaching negative

consequences of innumeracy, or a lack of math literacy, in real-world contexts, (b) a mechanistic explanation of the origins of natural number bias, (c) differing goals across disciplines for circumventing numerical biases via interventions, and (d) recommendations for ways to improve math education in the service of battling innumeracy.

\section{Innumeracy's Far Reach}

Many people struggle with numeracy, "the ability to access, use, interpret, and communicate mathematical information and ideas, in order to engage in and manage the mathematical demands of a range of situations in adult life" (OECD, 2016, p. 49). Strikingly, results from the Programme for International Student Assessment (PISA; OECD, 2018;

https://www.oecd.org/pisa/) show that U.S. 15-year-olds perform below the international average on math literacy, operationalized as "mathematics knowledge and skills to meet real-life challenges." This is troubling because low numeracy earlier in life relates to poorer math performance in later childhood (Siegler et al., 2012) and has health and financial implications for outcomes in adulthood (NMAP, 2008; Peters et al., 2019). ${ }^{1}$

\footnotetext{
${ }^{1}$ On the one hand, some research has shown that socio-economic status and low numeracy are linked (Ramani \& Siegler, 2009). Low-income children have different numerical experiences prior to formal schooling than do their middle-income age mates, and numerical board game interventions have been shown to close the gap in numerical magnitude understanding between these two groups of children (Ramani \& Siegler, 2008; 2009; Siegler \& Ramani, 2008). However, the same researchers have reached different conclusions when analyzing other nationally representative data sets. That is, a host of demographic factors, including elementary-aged children's general intellectual ability and parental income and education level, did not predict Algebra performance 5 or 6 years later (Siegler et al., 2012). The causes and effects of low numeracy are important topics for continued research.
} 


\section{LEVERAGING MATH COGNITION}

Misunderstanding the ways in which numerical magnitudes relate to one another is one source of innumeracy. Difficulties with ratios are due in part to ratios being relational constructs (Sidney \& Thompson, 2017; Siegler et al., 2011) -- the first quantity must be interpreted in relation to the other quantity (e.g., 3 of 7 parts for the ratio 3:7, or its fraction form 3/7; Paik \& Mix, 2003), and both of these units must be interpreted relative to the whole unit (e.g., 7 of 7 parts is the whole). It is for this reason that ratios can be thought of as analogous to Piaget's class-inclusion problem used to assess children's relational reasoning (see also Reyna, 1991; Wolfe \& Reyna, 2010). For example, when presented with an array of 3 red roses and 4 daisies, young children often respond that there are more daisies than flowers. This is likely because children focus on the two distinct subsets ( 3 red roses vs. 4 daisies) rather than the subset of 4 daisies relative to the whole set of 7 flowers.

Failure to engage in relational reasoning underlies people's difficulty understanding rational numbers and contributes to natural number bias (Alibali \& Sidney, 2015; Braithwaite \& Siegler, 2017; Fitzsimmons et al., 2020b; Lamon, 2020; Ni \& Zhou, 2005; Sidney \& Thompson, 2019; Siegler et al., 2013). This bias likely arises because of people's extensive experience with, and confidence in, dealing with natural numbers (Dehaene \& Mehler, 1992; Fitzsimmons et al., 2020a). From a young age, people have extensive experience reasoning with natural numbers. However, these experiences are narrowly constrained to reasoning about absolute magnitudes (e.g., 3 red roses). Experiences that focus on reasoning about relative magnitudes (e.g., how the number of roses relates to the total number of flowers) are less common and tend to occur later in development. Natural number bias arises when the parts are dissociated from the whole for quantities that mathematically exist in relation to one another. Furthermore, natural number bias is not relegated just to those individuals who are low in numeracy. Rather, it is a pervasive problem that impacts people of all ages (Alibali \& Sidney, 2015; Braithwaite \& Siegler, 
LEVERAGING MATH COGNITION

2018; Fazio et al., 2017; Ni \& Zhou, 2005; Opfer \& DeVries, 2008), cultures (Alonso-Diaz et al., 2019; DeWolf \& Vosniadou, 2015; Gómez et al., 2015; Van Hoof et al., 2020), and levels of expertise (Obersteiner et al., 2013; Reyna, 2004). This suggests that decision-making biases do not suddenly occur in adulthood and thus, may be amenable to earlier intervention.

Innumeracy exerts downstream consequences in educational, health, and financial contexts (Nelson et al., 2013; NMAP, 2008; Peters et al., 2019; Trevena et al., 2021). Natural number bias can lead directly to innumeracy in the health domain (rightmost section of Figure 1). Innumeracy, in turn, is also associated with avoidance of higher-level math courses and STEM careers (Ashcraft \& Kirk, 2001), which can impact access to higher education and earning potential (NMAP, 2008). Innumeracy is also related to negative outcomes in financial contexts (Peters et al., 2019) and arguably any context in which rational numbers must be accurately interpreted.

\section{Identifying a Common Driver of Innumeracy: Natural Number Bias}

Natural number bias is a broad phenomenon that accounts for a myriad of findings including overgeneralization of whole number arithmetic strategies when solving fraction arithmetic problems (Siegler et al., 2011), consideration of only natural numbers when evaluating possible values of variables (Van Hoof et al., 2015), and failure to recognize that between any two fractions there are an infinite number of other possible fractions (Vamvakoussi \& Vosniadou, 2010). For example, when presented with rational numbers, like $1 / 8$ and 1/4, people may fail to attend to the numerators because they are the same (Bonato et al., 2007; Opfer \& DeVries, 2008; Schneider \& Siegler, 2010; Thompson \& Opfer, 2008). Said another way, in the breast cancer vs. heart disease example above (1 in 8 vs. 1 in 4 ), people are more likely to only attend to the denominator, rather than considering the fraction's magnitude, because the denominators differ from one another, and the numerators do not. Knowing that 8 is 


\section{LEVERAGING MATH COGNITION}

greater than 4 , people may mistakenly decide that $1 / 8>1 / 4$. This is an example of natural number bias because this error demonstrates over-generalization of knowledge about natural numbers (that 8 is greater than 4) and a failure to comprehend the magnitude of the ratio formed by the relation between the numerator and denominator: $1 / 8=12.5 \%$ which is less than $1 / 4=25 \%$. Not only do children and adults sometimes fail to understand which fraction is larger, but natural number knowledge also interferes in estimating just how large (or small) fractions are, for example, considering $1 / 60$ to be closer to $1 / 1$ than $1 / 1440$ because 60 is closer to 1 than 1440 (Opfer \& DeVries, 2008; Thompson \& Opfer, 2008).

In Figure 1, we propose a novel developmental trajectory, drawing on research specifically from math cognition and education, that likely contributes to innumeracy. In this trajectory, we describe (a) the limitations of the perceptual system, (b) the processing systems capable of representing large approximate numbers, ratios, and magnitudes more generally, which are shared across ages, cultures, expertise levels, and species, (c) the statistical regularities in the environment and formal classroom instruction on rational numbers which could predispose people to the natural number bias, (d) critical individual differences that impact performance on pure numerical tasks and health decision-making tasks, and (e) the real-world consequences of natural number bias on innumeracy. The developmental trajectory identifies two critical inflection points for intervention-one in childhood, and one in adulthood-which are represented with the large gray arrows in the figure. First, we briefly describe the subcomponents of our novel developmental framework (section 3), then we provide more details about our claim that natural number bias is the overarching phenomenon that encompasses ratio bias, denominator neglect, and the 1-in-x phenomenon (section 4). Next, we describe how natural number bias may be adaptive in some contexts (section 5), individual 


\section{LEVERAGING MATH COGNITION}

differences influence decision making involving rational numbers (section 6), and some educational interventions that improve natural number bias (section 7).

\section{What Underlies the Natural Number Bias?}

3.1 Perceptual constraints ${ }^{2}$. From a historical perspective, research from as early as the 1800s has shown that the human perceptual system is limited in systematic ways. Consider the Weber-Fechner Law: for a person to notice a change in the intensity of a stimulus (e.g., How many additional candles beyond just one must be lit to notice a difference in brightness in a large, dark room?), the difference must reach a specific threshold proportional to the intensity of the original stimulus. In the case of the visual perception of nonsymbolic numbers (Figure 3), a person decides that 4 objects is greater in magnitude than 2 more quickly and accurately as compared to deciding that 104 objects is greater than 102 (i.e., size effect) because the ratio of the first pair is considerably larger than the ratio of the second. Furthermore, the more distant two numbers, the easier they are to discriminate from one another (i.e., distance effect;

Dehaene, 2011; Dehaene et al., 1998) and remember (Thompson \& Opfer, 2016; Thompson \& Siegler, 2010). Humans of all ages (McCrink \& Wynn, 2007; Xu \& Spelke, 2000), even those who lack a complex formal counting system (Pica et al., 2004), as well as non-humans (e.g., Dehaene, 2011; Dehaene et al., 1998; Rugani et al., 2016), can differentiate approximate magnitudes when they differ by a just-noticeable difference (i.e., that individual's threshold). Specifically, humans possess an early-emerging system (or systems) to process numerical and/or spatial information, although the exact nature and developmental trajectory of this system (or systems) and what exactly is processed has been debated (i.e., Approximate

\footnotetext{
${ }^{2}$ A detailed overview of the Weber-Fechner Law, approximate-magnitude system, approximate-number system, ratio-processing system and perceptual constraints more generally are beyond the scope of this paper. However, interested readers might consult Clarke and Beck (2021), Feigenson et al. (2004), Leibovitch et al. (2017), Matthews et al. (2015), and Newcombe et al., 2015 for overviews.
} 


\section{LEVERAGING MATH COGNITION}

Number System [ANS] used to process large approximate numbers ${ }^{3}$ : Feigenson et al., 2004;

Halberda et al., 2012; separate core knowledge systems to process number and space: Spelke

\& Kinzler, 2007; Ratio Processing System [RPS] to process rational numbers: Jacob et al., 2012; Matthews et al., 2015; Approximate Magnitude System [AMS] to process magnitudes of any kind: Leibovich et al., 2017; Newcombe et al., 2015). Constraints of the human perceptual system have implications for how humans reason about natural and other rational numbers.

\section{Figure 3}

A Non-symbolic Array of Dots in which Overall Surface Area is Controlled

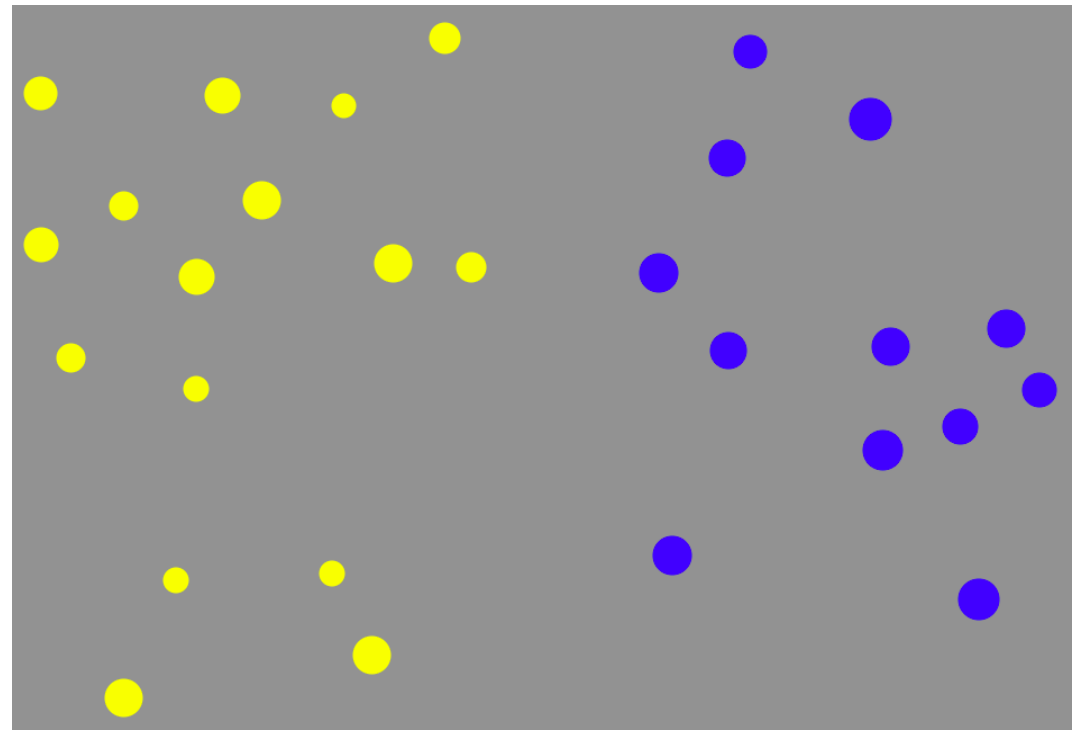

Note. Dot arrays like this one are accessible for research via https://panamath.org. These arrays can be interpreted in many ways. For example, people may be asked to decide which color is more numerous than the other. The correct answer is that there are more yellow than blue dots $(16>12)$. Or, people may also be given a cover story that asks them to think about the dots like pieces of candy in a jar, and that they should try to maximize their likelihood of choosing a yellow piece of candy because they taste the best (Fazio et al., 2014). In this jar, the ratio of yellow to blue is 16:12 or 4:3. This also means that the person has 16 out of 28 or a $57 \%$ chance of picking out a yellow piece of candy from this jar. If there were 8 yellow and 6 blue, the ratio would be the same, but expressed with different natural-number

\footnotetext{
${ }^{3}$ Recently, some researchers have proposed that the ANS processes both natural numbers and rational numbers, subsuming the RPS (Clarke \& Beck, 2021).
} 


\section{LEVERAGING MATH COGNITION}

components. There are an infinite number of ways to symbolically express this ratio. As indicated in the text, every example of a symbolic or a nonsymbolic ratio is also an additional experience with natural numbers. Thus, natural numbers are necessarily more prevalent in environmental input than rational numbers. Note that surface area is controlled for the dots in this figure; there are more yellow than blue dots, but some of the yellow dots are substantially smaller than some of the blue dots. This type of experimental control is crucial to show that infants and non-human animals have a specific, early emerging capacity for numbers, as opposed to other stimuli characteristics that covary with number (e.g., surface area, density).

\subsection{Natural numbers are extremely prevalent in the environment. Even though}

humans are equipped with an early emerging system which allows them to automatically process rational number information, the environment plays a key role in how humans process symbolic numbers (e.g., Braithwaite \& Siegler, 2018; Ni \& Zhou, 2005). Across many cultures, humans have substantially more experience with symbolic (i.e., Arabic numerals) natural numbers than other symbolic rational numbers. Given the structure of symbolic fractions, any experience with symbolic ratios, fractions, decimals, percentages, or whole number frequencies is necessarily also an experience with symbolic natural numbers that compose the ratio. For instance, every time that a person encounters the fraction $1 / 2$, they also encounter the natural numbers 1 and 2 . This is one likely reason ${ }^{4}$ that the fraction $1 / 2$ is rated as highly familiar-and more familiar than the equivalent fraction, 15/30 (Fitzsimmons et al., 2020; Fitzsimmons \& Thompson, 2021). Since $1 / 2$ is composed of the numerator " 1 " and the denominator " 2 ," natural numbers more familiar than "15" and "30" (Dehaene \& Mehler, 1992), this may contribute to the overall impression of greater familiarity of $1 / 2$ relative to $15 / 30$.

Symbolic and non-symbolic natural numbers (magnitudes, such as a collection of objects or partitioned lengths; Boyer et al., 2008; Begolli et al., 2020) are prevalent in formal classroom environments as well as informal out-of-school environments (Bustamante et al., 2020; Carraher

\footnotetext{
${ }^{4}$ Half is likely a special case that is a very familiar fraction in its own right. This fraction occurs often in math textbooks (Braithwaite \& Siegler, 2018), children are asked to partition shapes into halves in the first-grade geometry strand of the CCSSM, and half is a benchmark fraction that children in fourth grade are encouraged to compare to other fractions to assess their magnitudes (CCSSO, 2010; Siegler \& Thompson, 2014; Siegler et al., 2011).
} 


\section{LEVERAGING MATH COGNITION}

et al., 1985). People are acutely attuned to this numeric information, possibly because of the early emerging numerical knowledge described above as well as humans' sensitivity to patterns in the environment. In fact, even young children have a propensity to spontaneously focus on numeric information in their environments (Hannula et al., 2010; Chan \& Mazzocco, 2017), and prior to their first birthday, infants learn to recognize new patterns (e.g., ABB) that diverge from previously encountered statistical regularities in their environment (Marcus et al., 1999, Saffran et al., 1996).

The type and quantity of linguistic input about numbers that children receive at home can support their later math development (Eason \& Ramani, 2020; Levine et al., 2010; Pruden \& Levine, 2011). However, children's environmental input is biased because small natural numbers (e.g., 1, 2, 3) are more prevalent in the early linguistic environment relative to large natural numbers (e.g., 231, 232, 233, Dehaene \& Mehler, 1992).

The prevalence of natural numbers in the environment likely contributes to natural number bias. For example, children's experiences that illustrate how natural numbers like 15 and 30 are larger than 1 and 2 may contribute to their tendency to overestimate large-component (e.g., 15/30) relative to small-component (e.g., 1/2) equivalent fractions (Braithwaite \& Siegler, 2018). Additionally, their familiarity with fractions that have small relative to large natural-number components is associated with children's and adults' higher confidence when estimating equivalent fractions with smaller than larger components (Fitzsimmons et al., 2020a; Fitzsimmons \& Thompson, 2022). Furthermore, environmental input can lead to the types of math errors that children make. When the various fraction arithmetic problems found in popular elementary math textbooks were entered into a computational model as input, the model's errors resembled those made by children (Braithwaite \& Siegler, 2018). One common error involved the overapplication of whole-number arithmetic procedures to fraction-arithmetic 


\section{LEVERAGING MATH COGNITION}

problems. For example, adding across numerators and denominators leads to an incorrect answer on a fraction addition problem. Natural number bias errors are not limited to children in educational contexts but are also observed for adults in a Prisoner's Dilemma decision-making scenario. Adults were more likely to cooperate rather than defect when they were offered 300 cents in comparison to $\$ 3$ (Furlong \& Opfer, 2009) because $300>3$ even though the monetary incentives were equivalent (i.e., 300 cents $=\$ 3$ ).

Modifying the environment can have dramatic educational implications. Moss and Case (1999) tested an experimental curriculum that changed the order in which rational number types were introduced to leverage children's understanding of percentages towards understanding decimals and fractions. This intervention improved children's understanding of rational numbers and reduced natural number bias relative to a control group of children who learned about rational number types in the typical order (fractions first, followed by decimals). Moss and Case's intervention was effective but was implemented over the course of several months. Importantly, however, even small modifications can minimize common mathematical misconceptions, as has been shown with a different misconception relating to children's understanding of the equal sign (McNeil, 2008; McNeil et al., 2014). Young children have extensive practice with "right blank" addition problems (i.e., $2+3=\ldots$ ) and subsequently develop a misconception that the equals sign means "find the answer" rather than an indication that the quantities on both sides should be the same. By simply practicing problems in a workbook with the blanks on the left (i.e., ___ $=2+3$ ), children developed a more conceptual understanding of equivalence (i.e., what's on the left of the equation must be equal to what's on the right) that persisted across 5-6 months. These studies suggest that the nature of children's experiences in classrooms affects their reasoning. Given that people have substantially more experience with 


\section{LEVERAGING MATH COGNITION}

natural numbers as compared to other rational numbers, these common experiences may influence their reasoning when they encounter numerical information in everyday life.

\subsection{Individual differences impact rational number understanding. There are} important individual differences (e.g., objective and subjective numeracy, magnitude understanding, math attitudes, math anxiety, confidence) that may impact how accurately people interpret numerical risk information. As we describe below in section 6 , it is imperative to consider a variety of individual differences when evaluating how people reason about rational numbers during health decision making.

\subsection{Natural and rational numbers are not coherently integrated in formal}

instruction. In the U.S., the Common Core State Standards in Math (CCSSO, 2010) recommend that symbolic fractions (e.g., 3/7) not be formally introduced in math classrooms until third grade. However, by this point in the curriculum, children have had nearly a decade of formal and informal experiences with natural numbers that can help or hinder them as they reason about fractions in formal and informal math contexts.

The disconnect between natural numbers and fractions is exacerbated because U.S. teachers receive little guidance on how to emphasize the shared mathematical structure of natural numbers and fractions to their students (although, Siegler et al., 2010 does offer suggestions for using number lines to illustrate connections between natural numbers and fractions). In fact, the Common Core State Standards exclusively focus on children's ability to understand absolute magnitudes of whole numbers prior to third grade. The standards focus on fractions as relational magnitudes over a protracted period, from third through fifth grade, and then address ratios and proportions in sixth grade. Thus, it is likely that children are learning about different aspects of rational numbers from different teachers across several years of formal schooling. Even after years of fraction instruction, middle school students (Siegler et al., 


\section{LEVERAGING MATH COGNITION}

2011), community college students (Schneider \& Siegler, 2010), and even college students at selective universities (Fazio et al., 2017) succumb to fraction errors that arise from their misapplication of natural number knowledge to all other numbers (Siegler, 2016).

\section{Natural Number Bias is the Overarching Phenomenon}

Several phenomena identified in the field of decision making--ratio bias, denominator neglect, and the 1-in-x phenomenon (described below)--are the result of natural number bias (i.e., the tendency to focus on natural numbers and natural number strategies when reasoning about ratios). Our innovative interpretation is that natural number bias is the overarching construct that subsumes these phenomena identified in the decision-making literature.

At its core, the natural number bias is a failure to engage in relational reasoning (Gentner, 1983) by considering concepts in isolation rather than in relation to one another. ${ }^{5}$ Rational numbers and natural numbers share many common features, which can be adaptively leveraged when people attempt to apply their knowledge about natural numbers when reasoning with rational numbers (Sidney, Thalluri, et al., 2019; Yu et al., 2020, 2021). However, as our many examples have illustrated, overgeneralizing and misapplying the properties of natural numbers to rational numbers can lead to inaccurate estimates of rational number magnitude. In general, this is problematic and can lead to several biases in decision making, including ratio bias, denominator neglect, and the 1-in-x phenomenon (described below). These biases, which are just different instances of failure to engage in relational reasoning to process rational number magnitudes, can hinder accurate estimates of health statistics presented as rational numbers, which may have adverse consequences for health decision making.

\footnotetext{
${ }^{5}$ Some researchers would argue that to reason about similarity, one would need to notice what is distinctive, or different (Hunt, 2013). In this way, people may be considering alignable differences across stimuli as they compare them (Markman \& Gentner, 2000). More research is needed to assess the "structure-seeking" tendencies (Sidney \& Thompson, 2019; cf Wall et al., 2015) of people as they reason about rational numbers in pure numerical and applied contexts.
} 


\section{LEVERAGING MATH COGNITION}

4.1 Ratio bias and denominator neglect. Ratio bias, also known as denominator neglect, occurs when people focus on the natural numbers of a ratio. This bias has been shown in probability scenarios, such as giving people a choice between two bowls of jellybeans, one containing 1 red and 9 white and another containing 9 red and 90 white and asking them to choose which bowl would optimize their likelihood of choosing a red jellybean. In these scenarios, people will often choose from the bowl with a larger absolute number of red jellybeans (9 vs. 1), even when the proportion of red to white jellybeans is lower in that container $(9 / 100=9 \%$ vs. $1 / 10=10 \% ;$ Denes-Raj \& Epstein, 1994; Peters et al., 2006).

Critically, it is also an example of natural number bias, a failure to attend to the relation between two numbers but instead focus on each quantity in isolation. Studies in math cognition have conducted analyses of the open-ended strategy reports in which children and adults describe how they estimated and compared fraction magnitudes. It is common for people to explicitly mention in their strategy reports that they focused on numerators in isolation (Fazio et al., 2017; Sidney, Thalluri et al., 2019; Siegler et al., 2011; Siegler \& Thompson, 2014; Thompson et al., 2021). People also focused on just numerators early in the COVID-19 pandemic when the news media and politicians claimed that the seasonal flu was more common than COVID-19 because the absolute number of flu deaths were greater than the absolute number of COVID-19 deaths (Mielicki et al., 2021; Netburn, 2020; Scheibe et al., 2021; Thompson et al., 2020, 2021). This misunderstanding of case-fatality rates likely influenced people's beliefs that COVID-19 was less of a threat than the seasonal flu. Therefore, given that natural number bias involves either a focus on numerators or denominators in isolation, we argue that it is the overarching phenomenon which encompasses ratio bias and denominator neglect. 


\section{LEVERAGING MATH COGNITION}

4.2 1-in-x phenomenon. According to research on the 1-in-x phenomenon, people overestimate risks represented with one as the numerator (e.g., 1 in 5) relative to equivalent risks with a larger numerator (e.g., 15 in 75) (Pighin et al., 2011; Sirota et al., 2018;

Zikmund-Fisher, 2011). It is important to note that the phenomenon in which people overestimate the magnitude of ratios with smaller relative to larger numerator and denominator components is not specific to ratios with a numerator of one. For example, some adults demonstrated a reverse bias when they estimated the location of equivalent ratios on number lines (Fitzsimmons et al., 2020b), or when they were more accurate at comparing fractions that were incongruent relative to congruent with the order of natural numbers (e.g., 11/19 > 23/52, even though 11 and 19 are smaller natural numbers than 23 and 52; Obersteiner et al., 2020; Reinhold et al., 2020). Their responses suggested that they used the heuristic that smaller components = larger magnitudes. This heuristic may develop based on their experiences that, in general, ratios with larger denominators have smaller magnitudes. Thus, the 1-in-x phenomenon, in which 1 in 5 is overestimated relative to 15 in 75 , is similar to biases for ratios with numerators other than one.

Children and adults are influenced by the size of the independent natural number components of ratios in complex ways. It is important for future research to investigate the conditions under which people demonstrate the larger components = larger magnitude or the smaller components = larger magnitude bias.

\section{Adaptive Strategy Choice: Is Natural Number Bias Always Bad?}

Is natural number bias always a bad thing, or in some contexts is automatic processing of natural number components of a ratio a more efficient strategy than computing the ratio's magnitude? According to the adaptive strategy choice account (Alibali \& Sidney, 2015; Fazio et

al., 2017; Fitzsimmons et al., 2020b; Siegler, 1996), people adaptively choose which strategy to 


\section{LEVERAGING MATH COGNITION}

deploy depending on interactions among characteristics of the task at hand, the specific natural numbers involved in the stimuli, recent experiences, and individual differences, such as objective math ability (Alibali \& Sidney, 2015; Fazio et al., 2017). Even when people encounter the same problem a second time, they may use a different strategy to solve it (cf. strategy variability: Siegler, 1994). That is, strategy variability can be viewed as advantageous, adaptive, and predictable under some circumstances (Fazio et al., 2017; Fitzsimmons et al., 2020b; Sidney, Thalluri, et al., 2019).

One case in which attending to only the numerators or denominators in isolation may result in efficient strategies is when people are asked to compare two unit fractions in a pure numerical context $(1 / 2,1 / 31 / 4,1 / 5,1 / 6,1 / 7,1 / 8$, and $1 / 9)$ to choose the larger magnitude. In this case, it is more adaptive and efficient to use natural number strategies (e.g., 8 is less than 9, so based on the smaller components = larger magnitudes heuristic, 8 is a bigger share of the whole) than to precisely calculate the ratio's magnitude (Bonato et al., 2007; Schneider \& Siegler, 2010). By relying on the heuristic that larger denominators typically result in unit fractions that have smaller magnitudes relative to the same whole unit, people can ignore the numerators all together in their unit-fraction comparisons. Based on the adaptive strategy choice account, strategy variability in people's approach to rational numbers is not only meaningful (i.e., not random) and predictable (Fazio et al., 2017; Sidney, Thalluri et al., 2019), but provides opportunities to shape people's thinking by subtle manipulation of the problem-solving context (e.g., asking people to compare unit fractions to each other instead of other types of fractions).

It is an open empirical question whether cognitive biases, such as natural number bias, have the potential to lead to positive health intentions and behaviors. For example, if the woman who is trying to make sense of the 1 in 8 risk of breast cancer in her lifetime mistakenly thinks about just the denominator and reasons that 8 is a pretty big number, at least relative to 4 (i.e., 


\section{LEVERAGING MATH COGNITION}

heart disease denominator), she might perceive her lifetime risk for breast cancer as greater.

Even if her risk estimate is not objectively accurate, her heightened risk estimate, due in part to the risk being presented in 1-in-x format, might still prompt her to adhere to recommended health behaviors, such as yearly mammograms after the age of 50 and monthly breast self-exams.

Some health decision-making researchers have suggested that the 1-in-x format be adopted to communicate health risks in a more personally meaningful way, on the premise that one possible reason why small-probability risks might be overestimated is that the format encourages people to think more about themselves or another individual as the " 1 " in the numerator (Pighin et al., 2011). However, others (Cuite et al., 2008; Waters et al., 2016; Zikmund-Fisher, 2011, 2013) have warned that the 1-in-x format should be avoided when communicating health risks because this format is likely to result in misunderstanding--typically, overestimation--of personal health risks. The 1-in-x format does persist in health communications, such as the breast cancer and heart disease statistics the woman was considering above (see https://www.cancer.org/cancer/cancer-basics/lifetime-probability-of-developing-or-dying-from-ca ncer.html).

Instead, we suggest that percentages might be considered easier to comprehend than the 1-in-x format. Mathematically, percentages involve use of a common unit ("by the 100," from the definition of percent as per (by) cent (100)), which facilitates the process of comparing relative quantities. Even though percentages are a relational construct, they perceptually look like whole numbers (Sidney et al., 2021; Thompson et al., 2021) because they convey "multiples" of a common unit (i.e., 100 iterations of the unit, 1/100). This feature of percentages enables individuals to effectively apply their knowledge about natural numbers when processing 


\section{LEVERAGING MATH COGNITION}

ratios. In fact, people can just disregard the percentage sign in $75 \%$ and think about it like 75 because they are so familiar with the fact that 75 is a big number relative to 100 (Siegler \& Opfer, 2003).

There are several lines of work that support communicating health risks as percentages ${ }^{6}$. Math educators (Moss \& Case, 1999) have proposed that percentages may function as a conceptual bridge between more familiar natural numbers and less familiar fractions. Also, people endorse more positive attitudes toward percentages than fractions (Mielicki et al., 2021; Sidney et al., 2021). Thinking about percentages can engage knowledge about natural number magnitudes. Reasoning about percentages between 0 and 100 as natural numbers may cause natural number bias to exert fewer negative effects, but only in some cases (e.g., when comparing magnitudes but not in multiplicative contexts). For example, it is not mathematically accurate to add percentages in the same way that one adds together natural numbers. That is, $20 \%$ off an original price plus another $10 \%$ off is not the same as $30 \%$ off the original price (see Cuite et al., 2008 for empirical evidence in the health decision-making domain).

In summary, the natural number bias encompasses other cognitive biases studied in the decision-making literature. According to the adaptive strategy choice approach, natural number bias is maladaptive in most contexts, but can sometimes be adaptive. Future work could explore ways for health communicators to adapt materials to leverage the natural number bias such as using percentages to communicate about ratio information in some contexts.

\section{Consistency in Measurement and Accounting for Individual Differences}

Not only do math cognition and decision-making researchers use different terminology, but they also rely on different validated and reliable measures to assess people's objective and

\footnotetext{
${ }^{6}$ According to some decision-making researchers (Gigerenzer \& Hoffrage, 1995), natural number frequencies (e.g., 12 in 100) are preferred over percentages because percentages can lead to inaccurate calculations in some contexts. See Sloman et al. (2003) for an alternative view.
} 


\section{LEVERAGING MATH COGNITION}

subjective math skills. In the decision-making literature, measures of objective numeracy, such as the Rasch-based numeracy scale (Weller et al., 2013) and the Berlin numeracy scale (Cokely et al., 2012) require people to calculate to solve math problems. As it turns out, many people have more negative attitudes about math involving fractions and percentages than about math involving natural numbers (Sidney et al., 2021) and prefer to avoid doing math. Furthermore, objective numeracy scales are often presented as word problems, which are notoriously difficult to parse (Koedinger \& Nathan, 2004) and may result in impulsive calculation (Schiller, 2020). Impulsive calculation (i.e., "plug and chug") occurs when people read a math problem and immediately begin solving it before trying to make sense of the underlying structure of the problem (Chi et al., 1981).

Health decision-making researchers also rely on the subjective numeracy scale (Fagerlin et al., 2007) to measure self-reported math ability without the need for participants to calculate their answers, which avoids the issues mentioned above pertaining to objective measures. The subjective numeracy scale is correlated with objective measures of numeracy, but is considered a distinct construct (Peters et al., 2019; Waters et al., 2018). The scale is preferable to objective measures because it is quicker to administer.

Our team has observed that objective and subjective numeracy scales are predictive of health decision-making precisely because these scales tap into understanding of ratios: objective measures are composed of items that assess the ability to calculate with ratios, and the subjective scale entails self-assessments about one's ability to work with fractions and percentages. Given that health statistics inherently involve rational numbers and require people to judge the magnitude of their own or others' risks, it is crucial that measures of math skills incorporate knowledge of ratios. 


\section{LEVERAGING MATH COGNITION}

There are several objective measures of math skills validated in the field of math cognition that could be administered by decision-making researchers. One promising candidate is the number-line estimation task, wherein participants are asked to estimate the location of numbers on a number line. Decision-making researchers have employed number-line estimation tasks to measure adults' symbolic number mappings (Peters \& Bjalkebring, 2015), but they have used a number line estimation task in the 0-1,000 range. By second grade, children make precise estimates in this numerical range (Siegler \& Opfer, 2003; Siegler et al., 2009), therefore, this measure may not be sensitive to individual differences in adults' rational-number understanding. Instead, researchers should specifically consider number-line estimation tasks with fractions because rational number understanding is crucial for interpreting health statistics. In numerical cognition research, performance on fraction number-line estimation tasks has been shown to be correlated with (Fazio et al., 2014; Siegler et al., 2011; Siegler \& Thompson, 2014), and predictive of, future overall math achievement (Siegler et al., 2012). Further, fraction number-line estimation tasks are quick to administer and avoid the shortcomings of word problems (Thompson et al., 2021). Recent evidence suggests that math cognition measures, including fraction number-line estimation tasks, predict health decision-making performance when entered simultaneously into models with objective and subjective measures commonly used in the decision-making literature (Thompson et al., 2021). That is, measures from math cognition are not redundant with measures from decision making, but rather explain unique variance in decision-making performance.

Another important individual difference that may impact people's ability to reason with health statistics is math anxiety, or an apprehension about math that occurs in the mere presence or anticipation of numbers and numerical information. Decision-making researchers should always consider the effects of math anxiety on health-decision making performance that 


\section{LEVERAGING MATH COGNITION}

involves participants attempting to interpret numerical health statistics. Math anxiety can be reliably assessed with one item (see Ashcraft, 2002; Núñez-Peña et al., 2014). Recent research from members of our authorship team has indicated that adults are more math anxious about fractions and very large natural numbers than percentages and small natural numbers (Mielicki, Wilkey, et al., 2021). If higher levels of math anxiety are linked to failure to reason deeply about numerical risk information or avoidance of numbers altogether (Thompson et al., 2021), then this could have implications for health decision-making scenarios, which often involve ratios. Our recent work (Choi et al., 2020) indicated that math anxiety, but not induced stress, was associated with performance on objective and subjective numeracy measures. Crucially, girls and women of different ages are less precise than boys and men when estimating the magnitude of numbers in pure numerical contexts as well as health contexts (Geary et al., 2020; Hutchison et al., 2019; Rivers et al., 2020; Thompson \& Opfer, 2008; Woodbury et al., 2021). Girls and women are also less confident in their estimation performance even when controlling for overall estimation skills (Rivers et al., 2020; Thompson \& Opfer, 2008). In summary, individual differences, such as pre-existing math ability, confidence (Fitzsimmons et al., 2020; Rivers et al., 2020), math anxiety, and gender should always be taken into consideration to fully understand how people (mis)interpret numerical information as they make decisions about their health.

\section{Educational Interventions to Improve Risk Interpretation}

Decision-making researchers have devised ways to help people effectively evaluate health statistics in the moment (e.g., Wolf \& Reyna, 2009). In a common approach, researchers present the numerical health information via visualizations, such as icon arrays and risk ladders (Waters et al., 2020). A primary goal of these decision-making approaches is to help people extract the gist of the numerical information (Reyna, 2008) and better evaluate the presented 


\section{LEVERAGING MATH COGNITION}

statistics (Bonner et al., 2021; Trevena et al., 2021). In this way, the visuals remove the burden of computing ratios by presenting statistics as percentages, which can be easily "read off" the visual (e.g., 8 out of 10 rows of an icon array containing 10 ovals per row are shaded in, and the y-axis indicates $80 \%)$.

Although these types of approaches can be effective at helping people evaluate numerical health information in isolated instances, they typically do not provide people with the tools to effectively evaluate numerical health information in the absence of visuals or other such cognitive supports (e.g., activating relevant prior knowledge: Sidney, Thompson, \& Rivera, 2019; Sidney et al., 2022). In contrast, our team's approach has been to consider two inflection points (see thick gray arrows in Figure 1, which are expanded in Figure 2) during which the natural number bias can be inhibited or bypassed in childhood and adulthood. That is, we can teach children or adults how to understand ratios and subsequently transfer this learning to new contexts via the use of instructional interventions grounded in cognitive science principles, such as the use of analogies to familiar contexts and worked examples.

To summarize, there is a philosophical difference in how the decision making and math cognition literatures approach the problem of helping people make more mathematically accurate risk assessments. The health decision-making literature recognizes that clinicians do not have time to teach patients about math. Instead, health decision-making researchers rely on either structuring health communications in ways to (a) prevent activation of numerical biases, such as the natural number bias or (b) promote use of non-cognitive processes, such as visual perception, that bypass computations entirely (e.g., an icon array in which a percentage risk can be "read off" without counting). Teaching people how to do the math is a long-term strategy for addressing problems like the natural number bias; it is worth the extra effort because people might then be able to translate what they learned in one situation to future situations, rather than having to depend on always encountering a well-designed visual display (cf. Zikmund-Fisher, 2012). 


\section{LEVERAGING MATH COGNITION}

We will discuss our recent work implementing interventions with adults in section 7.3 and address educational interventions with children in section 7.4. First, we describe some research from math cognition that informs natural number bias interventions.

7.1 Magnitudes are the gist of rational numbers. Numerical magnitudes are the building blocks of all of mathematics (Siegler, 2016) and a common feature of all rational numbers (Siegler et al., 2011). This perspective aligns with the fuzzy-trace theory (Brainerd \& Gordon, 1994; Reyna, 2008). According to this theory, people can rely on the gist of numerical information (approximate or estimated magnitudes) or verbatim (exact) numerical information when making decisions. There is a developmental shift in relying more on gist with age (Reyna, 2012); "intuitive gist-based processing is considered more advanced than relying on verbatim information" (Reyna \& Brainerd, 1991; 2008). In accounting for gist and verbatim recall of numerical information, fuzzy-trace theory is a dual-processing model, and such models have been proposed by math cognition researchers to explain mechanisms underlying natural number bias. For instance, when reasoning with fractions, people must first inhibit their prepotent, automatic whole number response to later engage in more effortful, strategic reasoning and processing of the ratio's magnitude (Vamvakoussi \& Vosniadou, 2004; Van Hoof et al., 2020). The development of rational number understanding may follow a trajectory like that described by the fuzzy-trace theory. If we consider the gist, or essence, of rational numbers to be their approximate magnitudes, then learners typically move from reasoning with exact information (i.e., the size of the natural number components of a fraction) to applying more intuitive gist-based reasoning by considering approximate rational number magnitudes. People may be more likely to rely on the gist, or magnitude, of numbers when they have more robustly activated, or precise, mental representations of the magnitudes of those numbers (Alibali \& Sidney, 2015). If we can prompt or teach people to consider the gist of rational number 


\section{LEVERAGING MATH COGNITION}

magnitudes, for instance when estimating the magnitude of a health risk, this may help them avoid the pitfalls of the natural number bias and optimize decision making.

7.2 Number lines clearly illustrate numerical magnitudes. Teaching about the magnitudes of ratios using number lines - horizontal visual displays in which smaller numbers are located on the left side of the line and larger numbers are located on the right side of the line (see Figure 4) - capitalizes on prior natural number knowledge to build accurate fraction understanding in the middle grades of elementary school (Sidney et al., 2017; Yu et al., 2020, 2021) and in adulthood (Sidney et al., 2022). Number lines are often present in classrooms as they are a critical part of training children how to reason about the magnitude of numbers and compare those magnitudes to one another (see CCSSO, 2010; Common Core Standards Writing Team, 2011). Number lines have helped people of all ages more accurately interpret the magnitude of numbers relative to one another and to the endpoints of the line (Mielicki et al., 2021; Siegler, 2016; Thompson et al., 2021; Woodbury et al., 2021). ${ }^{7}$ According to the Integrated Theory of Whole Numbers and Fractions Development (Siegler et al., 2011), number lines are a useful tool to show what whole numbers and fractions have in common: magnitudes whose values can be placed on number lines.

Yu and colleagues $(2020,2021)$ aligned a number line ranging from 0 on the left to 8 on the right with a number line ranging from 0 on the left to 1 on the right. Then, children marked the location for 3 on the $0-8$ number line and were then more accurate when placing $3 / 8$ on the 0-1 number line because this fraction is located at the very same point on the number line: $38 \%$ of the way across the number line from left-to-right. Children can observe how the partitions for 1,2 , and 3 out of 8 units are the same as $1 / 8,2 / 8$, and $3 / 8$ out of $8 / 8$ units (Steffe $\&$ Olive,

\footnotetext{
${ }^{7}$ The Common Core State Standards Writing Team (2011) created some draft resources to help teachers use number lines as they represent ratio relationships in their lessons. See https://commoncoretools.files.wordpress.com/2012/02/ccss_progression_rp_67_2011_11_12_corrected.p df
} 


\section{LEVERAGING MATH COGNITION}

2009). In Figure 4, we visualize the way in which $3 / 8$ equals 3 copies of a length of $1 / 8$ from 0 , and how this line segment is analogous to creating 3 equal copies of a length of 1 whole unit from 0 .

Number lines also capitalize on spatial-numeric relations to help people easily visualize numerical magnitudes (Dehaene, 2011; Opfer et al., 2010). In cultures with left-to-right orthographies, the mental number line is oriented with smaller numbers located on the left and larger numbers located on the right just like the number line visual display. Number line visual displays are thought to be a central conceptual structure (Griffin et al., 1994) to help children and adults map their mental magnitudes onto physical space.

\section{Figure 4}

Bootstrapping Whole-Number Knowledge to Improve Fraction Estimation Performance

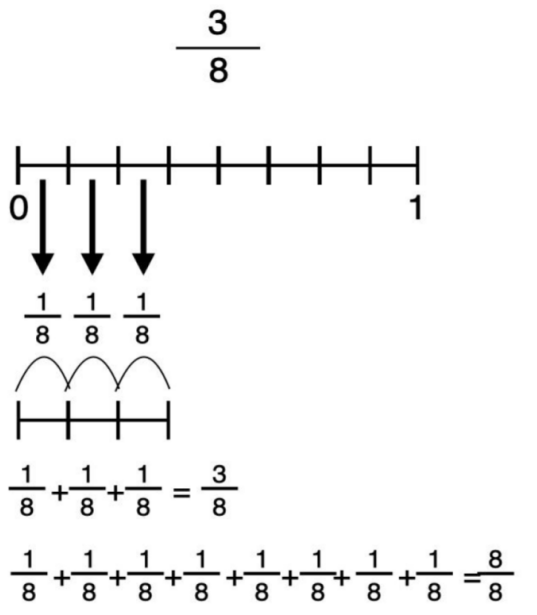

Note. Iterating the unit of 1 three times shows the location of 3 on the $0-8$ number line on the left. Iterating the unit of $1 / 8$ three times shows the location of $3 / 8$ on the $0-1$ number line on the right. In this way, knowledge about natural numbers can be bootstrapped to better understand fractions. 


\section{LEVERAGING MATH COGNITION}

Finally, number lines may make it much easier to identify and relationally reason about the part versus the whole to help people successfully solve class-inclusion problems (Reyna, 1991). In Figure 6, Panel B, the red line that stretches from the left of the number line to the vertical arrow indicates the magnitude, or the part; the end of the number line represents the whole. Conversely, because the icon arrays commonly used to present health statistics include discrete, compared to continuous, magnitudes, it is possible that these icon arrays may bias people to count and compare subsets of icons (red vs. gray ovals), rather than compare the magnitudes of each subset relative to the whole (red vs. all ovals) as has been found in prior research comparing discrete and continuous formats of ratios (Begolli et al., 2020; Boyer et al., 2008). The extent to which discrete icon array formats encourage counting strategies in health contexts is an empirical question for future research (e.g., Stone et al., 2003).

7.3 Interventions to address decision-making biases in adults. Our team has successfully implemented interventions aimed at reducing natural number bias in adults. One such intervention, employed by Thompson and colleagues (2021), is described in more detail in Figure 6 . This intervention featured several components informed by cognitive science research, including worked examples, analogies to familiar contexts, and using number lines to represent rational numbers. Of note, this educational intervention (Figure 6A and Figure 7) incorporated procedural instruction (i.e., step-by-step procedure for translating from a decimal to a percentage) as well as conceptual instruction (i.e., deaths must be considered relative to total infections; flu case-fatality rate is a very small number less than $1 \%$ and much closer to $0 \%$ than $5 \%$ ). Procedural and conceptual knowledge develop in tandem with one another (Rittle-Johnson, 2017). We trained participants on how to carry out the correct calculation procedures in case some adults lacked the relevant prior knowledge to reason about rates. We also included conceptual training to explain why the procedures work the way that they do. 


\section{LEVERAGING MATH COGNITION}

Conveying the conceptual information allowed us to highlight the numerical magnitudes of the death-to-infection ratios to help participants override their bias to consider the numerators or denominators in isolation. Of course, it is an open question for future research to assess whether these "light touch" interventions help adults continue to bypass their cognitive biases as they attempt to interpret health statistics in contexts in the future. Research inside (Thompson \& Siegler, 2010) and outside of the domain of mathematics (Shtulman \& Valcarcel, 2012) has shown that naive understanding involving biases can be suppressed, but not necessarily eliminated, by instruction.

Helping adults translate among equivalent rational number types more effectively may also help them to bypass the natural number bias. Adults may be unaware that there are an infinite number of numbers between any two fractions, and any given fraction can be represented in an infinite number of ways as equivalent fractions, decimals, and percentages (e.g., $1 / 4,0.25,25 \%$, and 25 of 100 all represent the same magnitude). Alerting adults that the natural number bias exists may prompt them to slow down and "make sense" of a fraction-related math problem (i.e., rely on relational reasoning). This may encourage people to employ more effective strategies to translate rational number information into an easier-to-interpret format (Alibali \& Sidney, 2015; Fazio et al., 2017; Fitzsimmons et al., 2020b; Mielicki et al., 2021; Moss \& Case, 1999; Sidney, Thalluri et al., 2019; Siegler et al., 2011; Siegler \& Thompson, 2014; Thompson et al., 2021) rather than impulsively calculating (Schiller, 2020) and over applying natural number knowledge to fraction problems. Such interventions would help adults with low numeracy overcome their misunderstanding of rational numbers to engage strategically with rational number magnitudes (see Figure 5 from Schiller et al., 2022; Alibali \& Sidney, 2015; Fitzsimmons et al., 2020b). This is important because adult caregivers 


\section{LEVERAGING MATH COGNITION}

and teachers can pass their correct or incorrect understanding of rational numbers along to

children.

\section{Figure 5}

Translating Among Fractions, Decimals, and Percentages Can Help People Accurately Interpret the Magnitude of Rational Numbers.

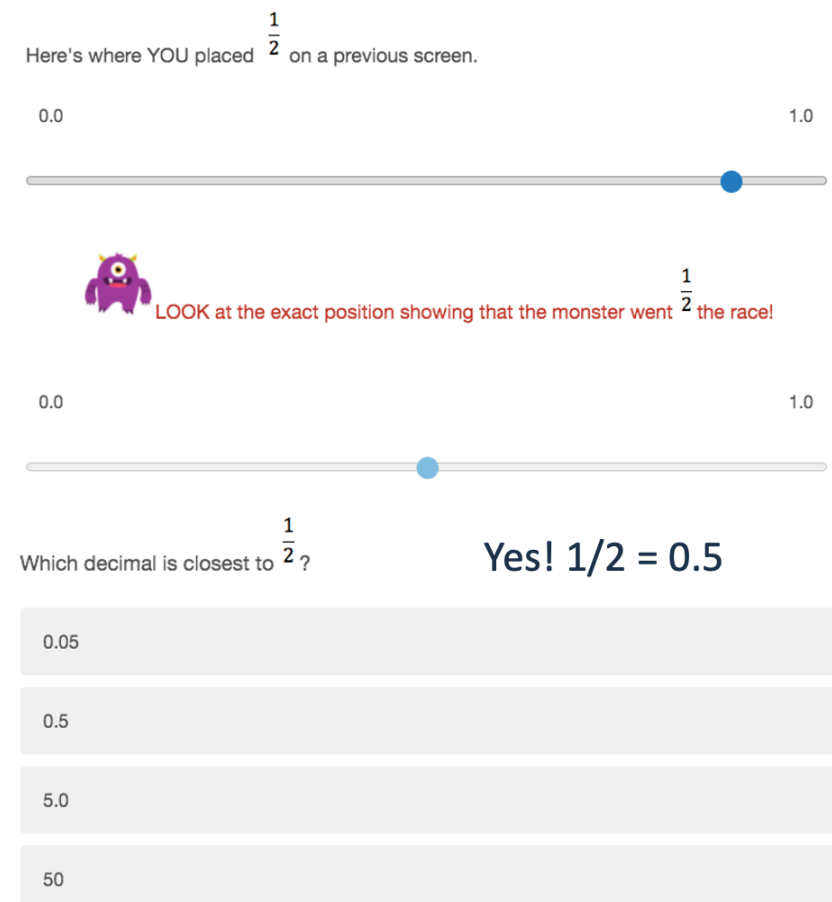

Note. College students, who engaged with a playful educational intervention about monsters racing along a number line, demonstrated improvements in their ability to translate among fractions, percentages, and decimals (Schiller et al., 2022). Translation skills are helpful to adults as they attempt to reason about the magnitude of health risks or statistics in difficult-to-handle formats, such as the 1 -in-x format.

\section{Figure 6, Panel A}

Survey Flow for Thompson et al. (2021) 


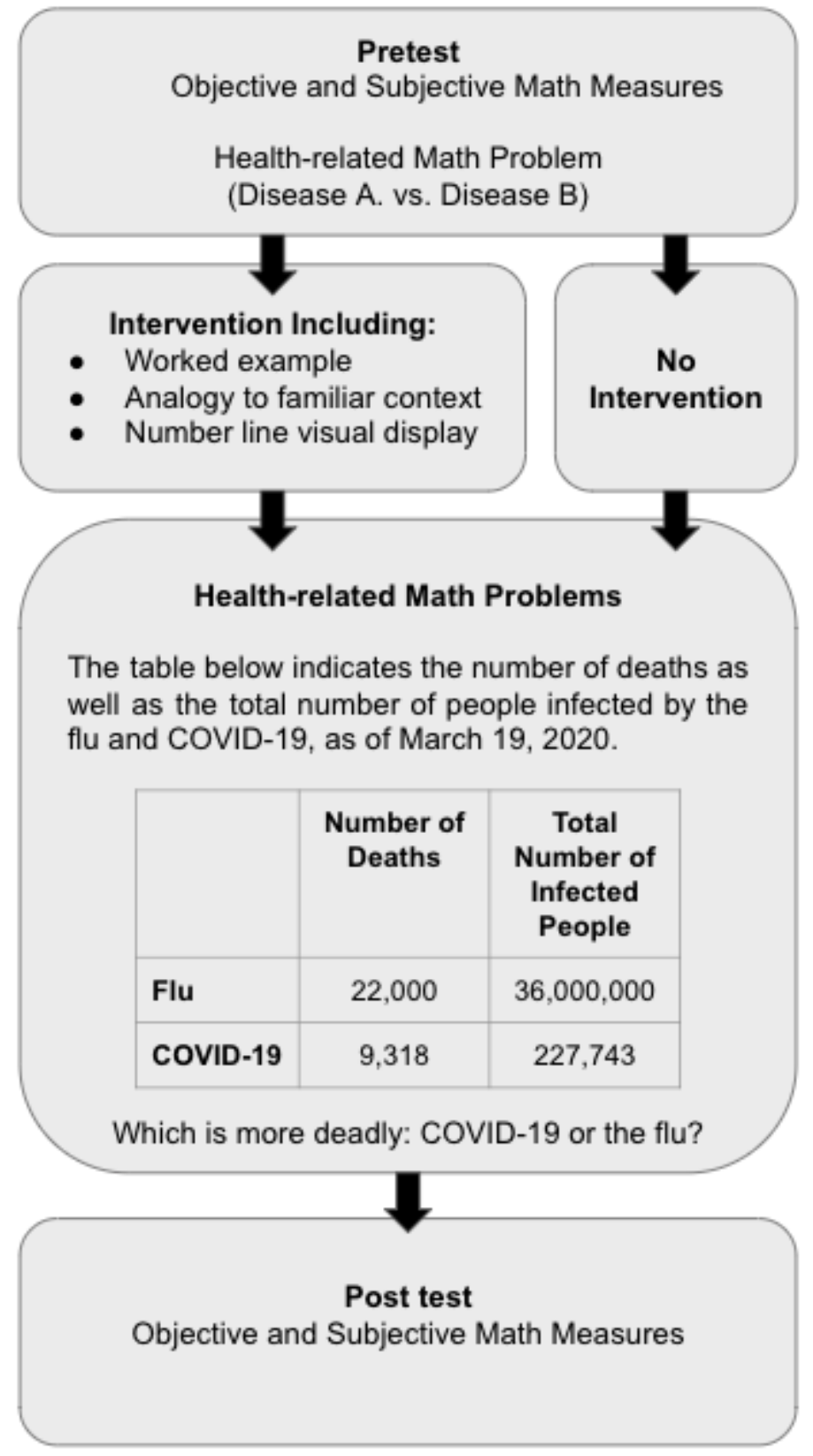

Note. At pretest, a national panel of adults completed objective and subjective math measures and a health-related math problem in which they compared the number of people who died from unnamed Disease A vs. Disease B and the total number of people who were infected with Disease A vs. Disease B. Then, half of the participants were randomly assigned to complete a brief, online educational intervention which included an analogy to a familiar, non-health context (i.e., decay rate of fruit in two orchards), a step-by-step worked example to calculate and compare case-fatality rates for COVID-19 and the flu, and number-line visual displays that compared the case-fatality rates for COVID-19 relative to the flu. The other half of the participants did not receive the educational intervention. Both groups completed problems that included 2x2 contingency tables, like the one shown here (see also Wolfe \& Reyna, 2010). Those participants who engaged with the educational intervention were more accurate on post-intervention health-related math problems pertaining to COVID-19 case-fatality rates than were participants who did not engage with the intervention. Furthermore, in a daily diary follow up across 10 


\section{LEVERAGING MATH COGNITION}

days after the intervention, those participants who engaged with the educational intervention reported higher COVID-19 worry and risk perceptions for themselves and others across portions of the diary relative to participants who did not engage with the intervention. This suggests that the intervention taught participants about the magnitude of the COVID-19 severity relative to the flu.

\section{Figure 6, Panel B.}

Example Visual Displays from Mielicki et al. (2021) 


\section{LEVERAGING MATH COGNITION}

As of early September, University A in the U.S. had tested 1,154 total students for COVID-19. At University A, 125 students had lab-confirmed cases of COVID-19, or tests that came back "positive." Another university in another part of the U.S., University B, had tested 22,470 total students for COVID-19. At University B, 249 students had lab-confirmed cases of COVID-19, or tests that came back "positive."
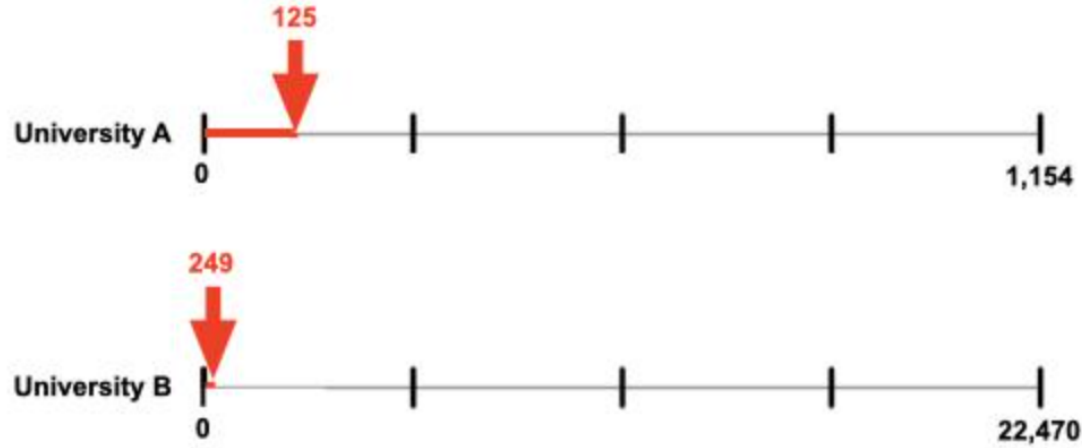

University A

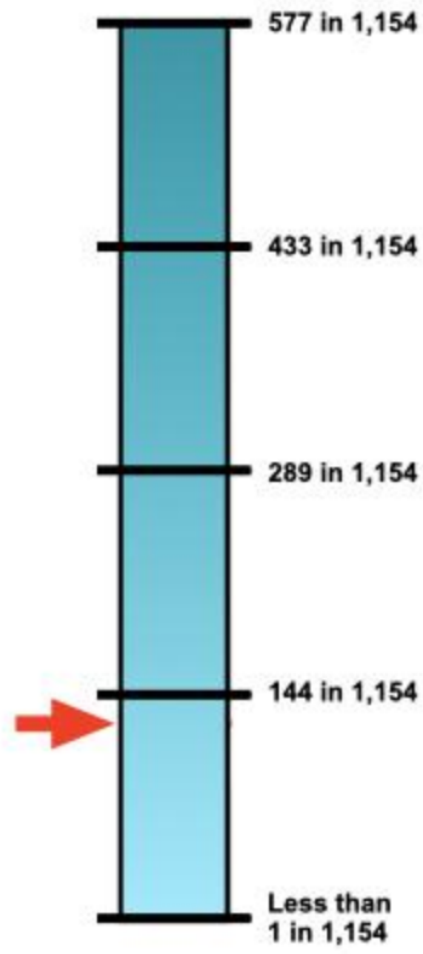

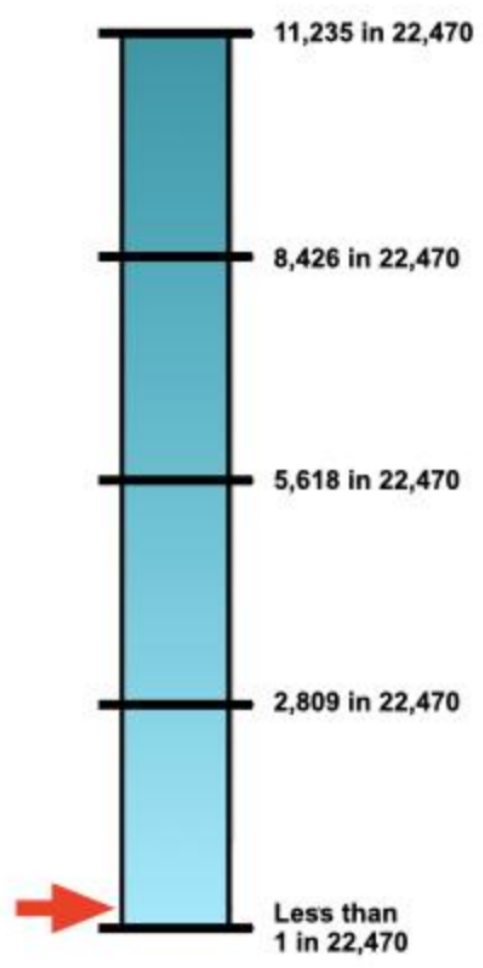

University B 


\section{LEVERAGING MATH COGNITION}

Note. From top-to-bottom: number-lines, risk ladders, and icon arrays. A sample of college undergraduates were randomly assigned to solve health-related math problems accompanied by one of three visual displays or no visual display at all. Number lines are not commonly used to convey risk information. However, participants who were randomly assigned to the number-line visual display condition were more accurate when solving COVID-19 related math problems than were participants in the risk ladder or icon array visual display conditions, which did not differ from the no visual display at all condition. Additionally, higher performance on the health-related math problems was associated with higher COVID-19 worry for oneself and others, higher perceptions of COVID-19 severity, and higher endorsement of intentions to engage in preventive health behaviors, even when controlling for baseline math skills. The number lines emphasized the size of the components of the ratio and allowed people to visualize the proportion of positive COVID-19 cases in University A vs. University B and directly compare these proportions-as a distance from the left endpoint of the number line- to one another to decide which University had the highest positivity rate. Future research should assess whether number lines help people make mathematically accurate health decisions in real-world, personalized risk contexts, too. 
LEVERAGING MATH COGNITION

Figure 7, Panel A

Excerpt From the Worked Example Used in Thompson et al. (2021)

\begin{tabular}{|l|l|l|}
\hline & Number of deaths & Total number of people infected \\
\hline Flu & 22,000 & $36,000,000$ \\
\hline COVID-19 & 9,318 & 227,743 \\
\hline
\end{tabular}

In order to determine which disease is the most fatal, you must consider the number of deaths RELATIVE to the total number of people who were infected.

Here's a step-by-step tutorial on how you can figure out the fatality rate for each disease.

\section{First, find the Flu fatality RATE.}

Divide the number of Flu deaths $(22,000)$ by the total number of people infected by the Flu $(36,000,000)$. If you plug these numbers into a calculator, you will see that $22,000 / 36,000,000=$ 0.00061 .

Transform this into a percentage by multiplying by $100: 0.00061 * 100=.06 \%$. This is the fatality rate for the Flu. That's a pretty small number that is less than $1 \%$ and closer to $0 \%$ than to $5 \%$.

\begin{tabular}{|l|l|l|l|}
\hline & $\begin{array}{l}\text { Number of } \\
\text { deaths }\end{array}$ & $\begin{array}{l}\text { Total number of people } \\
\text { infected }\end{array}$ & Fatality Rate \\
\hline Flu & 22,000 & $36,000,000$ & $\begin{array}{l}\mathbf{2 2 , 0 0 0} / \mathbf{3 6 , 0 0 0 , 0 0 0}=\mathbf{0 . 0 0 0 6 1}= \\
\mathbf{0 . 0 6} \%\end{array}$ \\
\hline COVID-19 & 9,318 & 227,743 & \\
\hline
\end{tabular}

Note. Procedural knowledge about how to calculate and compare case-fatality rates was conveyed in a step-by-step worked example by Thompson and colleagues (2021). Conceptual knowledge was conveyed by describing how the magnitude of the case-fatality rate for the flu was less than $1 \%$ and much smaller than $5 \%$. 


\section{Figure 7, Panel B}

Thompson and Colleagues' (2021) Worked Example Also Included Number Lines to Help

People Easily Compare Case-Fatality Rates Relative to One Another

Finally, compare the Flu's fatality rate $(0.06 \%)$ to COVID-19's fatality rate $(4.1 \%)$. You can see that the fatality rate is higher for COVID-19. In fact, as of March 19th, 2020 our best estimate is that it was 41 times more fatal.

One important thing to remember is that if you want to figure out a fatality rate, you have to take into consideration both the number of deaths as well as the total number of people infected for each disease.

Here is a graph to help you visualize the COVID-19 fatality rate (red in bottom bar) RELATIVE to the flu fatality rate (blue in top bar).

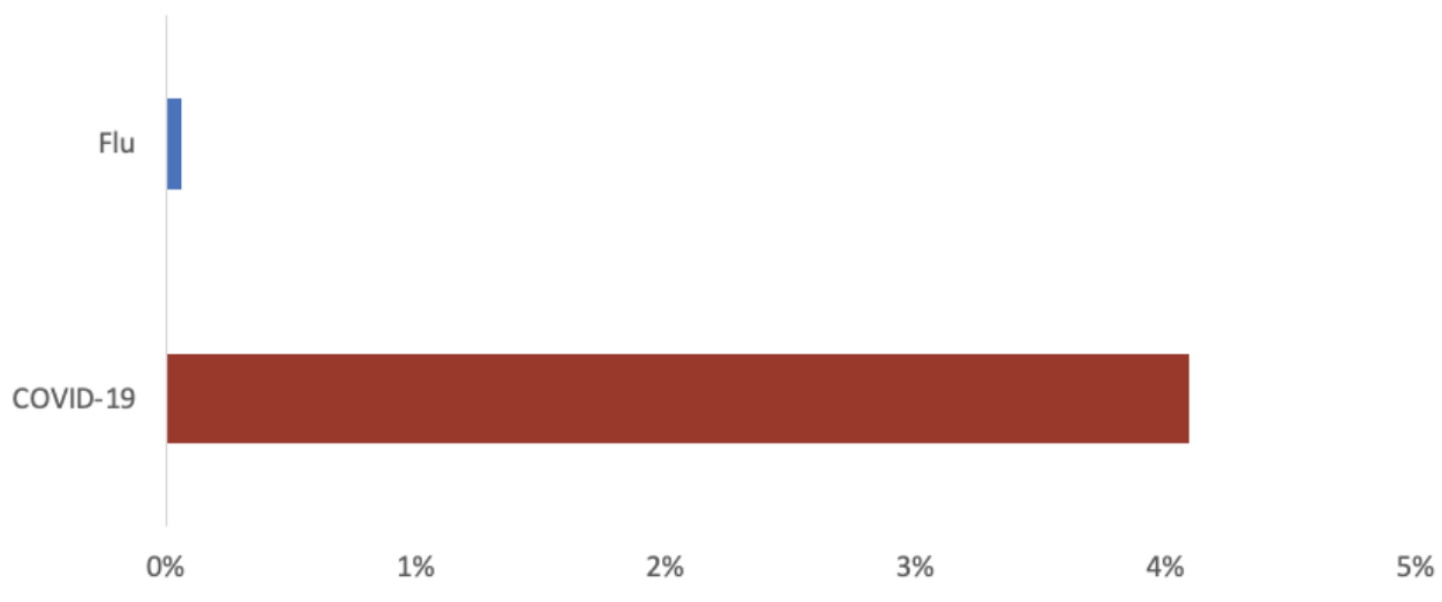

7.4 Interventions to head off health decision-making biases in childhood. If children learn how to avoid natural number bias - by being taught about the integrated nature of natural numbers, fractions, ratios, decimals, and percentages early in their formal math curriculum then according to our developmental framework (see Figure 2), they should be more likely to develop into adults who do not easily fall prey to numerical biases, thus ameliorating 


\section{LEVERAGING MATH COGNITION}

innumeracy in adulthood. Thus, to address natural number bias at this inflection point, math curricula can be restructured such that more productive connections are made between natural number knowledge and knowledge about rational numbers (e.g., Yu et al., 2020, 2021).

Evidence from an international assessment of students' math understanding (OECD, 2018) consistently indicates that students in the U.S. are below average in their mathematical literacy. These deficits in mathematical literacy have the potential for far-reaching implications for adults in daily life. There are also differences in teachers' pedagogical content knowledge pertaining to fractions in the U.S. relative to other countries with higher math achievement (e.g., Ma, 1999), and these differences may contribute to U.S. students' struggles with fractions. Addressing natural number bias during the childhood inflection point would be beneficial for young learners and could obviate the need to intervene with adults.

Implementing effective interventions at the childhood inflection point requires drawing on research findings about how rational number understanding progresses across development. ${ }^{8}$ Even six-month-old infants have a rudimentary understanding of ratios (McCrink \& Wynn, 2007), and by preschool, children can reason about continuous magnitudes in match-to-sample scaling tasks (i.e., a stuffed animal only likes drinks that have a certain juice-to-water ratio, and children have to identify a scaled-down match for this ratio; Boyer et al., 2008). Building on this early emerging understanding of nonsymbolic ratios, fractions are introduced in first grade in the context of partitioning shapes (CCSSM 1.G.A.3). However, fractions are not introduced in their symbolic form (i.e., $\mathrm{n} / \mathrm{m}$ ) until third grade, and are not defined in terms of division of relative quantities (i.e., $\mathrm{n} / \mathrm{m}$ = $\mathrm{n}$ divided by m; CCSSM 5.NF.B.3) until fifth grade. Interestingly, despite this protracted instructional sequence for rational numbers, sixth and eighth graders with years

\footnotetext{
${ }^{8}$ It is beyond the scope of this article to provide a comprehensive overview of this literature, however, interested readers can consult The Handbook of Mathematical Cognition (Campbell, 2005) and Sidney, Thompson, and Opfer (2019).
} 


\section{LEVERAGING MATH COGNITION}

of formal fraction instruction still make notable errors as they estimate the location of fractions on number lines (Siegler et al., 2011). Even college students make predictable mistakes as they reason about rational number magnitudes (Fazio et al., 2017; Schneider \& Siegler, 2010; Sidney, Thalluri, et al., 2019).

Addressing the natural number bias in math education requires a different solution than is currently employed in U.S. math curricula. Note that the sequence in which the Common Core State Standards in Mathematics (CCSSM) were initially ordered was not informed by rigorous, empirical research in all cases (CCSSM, n.d.; cf. Confrey and colleagues' (2014) concerns pertaining to mathematical progressions). In addition, sometimes the standards were underspecified, and educators received little guidance on how to implement the standards in classrooms (Nurnberger-Haag \& Thompson, in preparation; Sidney, Thompson, \& Rivera, 2019).

An unintended consequence of delaying the introduction of fractions as relational concepts and emphasizing natural number operations in early instruction is the tendency for students to think about quantities in absolute terms instead of relative to one another. One proposed solution is to emphasize ratios as relational concepts much earlier in instruction (see Ni \& Zhou, 2005). To help learners make the connection between natural numbers and fractions, teachers could emphasize the multiplicative, or measurement (Steffe \& Olive, 2009) aspect of fractions (see Figure 4). Another promising solution is scaffolding learners' understanding of rational numbers by helping them make connections across percentages, decimals, and fractions (Moss \& Case, 1999; Schiller, 2020; Schiller et al., 2022) rather than introducing these concepts separately across several grade levels. For example, students are not expected to translate a fraction into a percentage until 6th grade, and this translation is only expected for fractions with 100 as the denominator (CCSSO, 2010). More research is needed to 


\section{LEVERAGING MATH COGNITION}

assess whether introducing all rational number notations together in earlier grades would improve rational number understanding.

\section{Conclusions}

Our novel developmental framework provides an approach for thinking about the underlying mechanisms of innumeracy in adulthood. Innumeracy is not just a problem for some adults. People of various ages and expertise levels experience numerical biases, which likely stem from perceptual constraints, statistical regularities in the environment, and missed opportunities for drawing connections across natural number and ratio instruction in classrooms.

Further, our novel developmental framework takes into consideration that people know and use various strategies as they attempt to solve rational number problems. Some of these strategies lead to correct responses, whereas others do not. We have devised interventions that prompt people to stop and consider other strategies beyond the prepotent natural number bias response in which they focus on numerators or denominators in isolation rather than on how numerators relative to denominators express the magnitude of a ratio. Using number lines in our educational interventions makes the underlying magnitudes of the ratios more transparent (i.e., as a percentage of the total number line from left-to-right) to bypass the natural number bias. Number lines capitalize on what is similar across natural numbers and rational numbers to integrate numerical understanding across these number types.

An interdisciplinary approach to identifying and intervening on the precursors that contribute to the natural number bias can have unprecedented influence on decision-making outcomes in health, finance, and any other context involving rational numbers. Unbeknownst to researchers across diverse fields of inquiry, they may be attempting to answer similar research questions through the lenses of their own disciplines. However, collaboration can result in scientific breakthroughs with broader impact. In this call to action, we see significant merit in 


\section{LEVERAGING MATH COGNITION}

fostering collaborations across psychology, math education, health decision making, and health communication. Bringing together relevant expertise from these disparate domains can provide novel insights into adults' misconceptions pertaining to numerical health information.

\section{Glossary of Terms \\ Domain-General Process}

Relational reasoning: domain-general reasoning about the relations or components among concepts instead of the concepts or components in isolation. For example, a dog running behind a cat represents the "chasing" relation, and 3/7 represents the relation between the whole ( 7 of 7$)$ and the parts (3 of 7$)$.

\section{Cross-Species Number Systems and Capacity with Numbers}

Approximate number system: early emerging system that allows people and animals to perceive the approximate numeric value of sets without counting (e.g., 16 dots is more than 8 dots). Some researchers suggest that it is a system that allows people and animals to perceive magnitude instead of number because number co-varies with other continuous aspects of stimuli, such as surface area and density, which might instead be what people and animals are perceiving.

Magnitude processing system: the ability to process numerical magnitudes may be made possible by a general system that facilitates processing of magnitudes of any kind (e.g., length, brightness, weight, space).

Ratio processing system: early emerging system that allows people and animals to perceive approximate ratios without calculating (e.g., 16 blue dots for every 8 yellow dots is the same ratio as 2 blue dots for every 1 yellow dot). The extent to which this system is distinct from the approximate number system is debated. 
LEVERAGING MATH COGNITION

Number sense: basic ability that allows people and animals to reason with non-symbolic numerical magnitudes

\section{Numeric Ability (or Lack Thereof) and Preferences}

Numeracy: math ability or "understanding and use of mathematical concepts" (Peters, 2020); can be assessed with subjective (i.e., perceptions) or objective (i.e., calculations) measures. The OECD (2016, p. 49) defines it as: "the ability to access, use, interpret, and communicate mathematical information and ideas, in order to engage in and manage the mathematical demands of a range of situations in adult life."

Innumeracy: lack of, or deficit in, numeracy

\section{Types of Numbers}

Natural numbers: positive integers beginning with 1

Whole numbers: positive integers and 0

Rational numbers: fractions, percentages, decimals, and whole-number frequencies. In symbolic form, a rational number takes the fraction form $a / b$, where $a$ and $b$ are typically integers, and $b$ is not allowed to be equal to 0 . This symbolic form of a rational number explains why integers and fractions are instances of rational numbers.

Ratio: relationship between two quantities (e.g., three roses : five daisies, or a part related to a whole ([e.g., three roses : eight flowers]). The rational number magnitude associated with a ratio $a: b$, is $a / b$, where $b$ is not equal to 0 (e.g., the ratio of 3 cups of flour to 4 cups of sugar means there is $3 / 4$ cup of flour for each cup of sugar, or $\$ 50$ for 5 sandwiches means a rate of $\$ 10$ per sandwich. In this paper, a ratio a:b and its fraction or magnitude representation $\mathrm{a} / \mathrm{b}$ are used interchangeably, which also means that the two quantities $\mathrm{a}$ and $\mathrm{b}$ are sometimes referred to as numerator and denominator. 


\section{LEVERAGING MATH COGNITION}

Unit fraction: fraction with a numerator of one (e.g., 1/3 or 1/12). From a measurement or number line perspective, a unit fraction takes the form $1 / b$, where $b$ is a positive integer. They are called unit fractions because they represent the units that are iterated or copied in the fraction $a / b$, that is, $a / b$ means a copies or iterations of a $1 / b$ unit (e.g., $3 / 5$ means 3 copies or iterations of a $1 / 5$-unit).

Symbolic numbers: refers to presenting numeric information with Arabic or Roman numerals (e.g., 1, 1/2, III)

Non-symbolic numbers or ratios: refers to presenting number or ratio information with continuous line segments (e.g., one line segment is twice as long as the other), or discrete, countable objects, sounds, or events (e.g., $\uparrow \uparrow \uparrow \uparrow$ to represent 4).

Small-component equivalent fractions: fractions that often have single-digit numerators and denominators yet are defined relative to a large-component equivalent fraction that has the same magnitude, but larger numerator and denominator components (e.g., 1/2, a small-component fraction, is equivalent to 15/30, a large-component fraction).

Large-component equivalent fractions: fractions that often have double-digit numerators and denominators yet are defined relative to a small-component equivalent fraction which has the same magnitude, but smaller numerator and denominator components (e.g., $15 / 30$, a large-component fraction is equivalent to $1 / 2$, a small-component fraction).

\section{Types of Biases}

Natural number bias: also known as the whole number bias. An overgeneralization of natural number knowledge to all rational numbers. One example is attending to only the numerators or denominators of a fraction in isolation rather than considering the magnitude, or size, of the fraction. People may also judge fractions with larger numerators and denominators (e.g., 15/30) as larger than an equivalent fraction with smaller components (e.g., 1/2). 


\section{LEVERAGING MATH COGNITION}

Ratio bias/denominator neglect: only considering the numerator, and not the denominator, when reasoning with a fraction or ratio.

1-in-x phenomenon: refers to presenting risk information as 1 over a denominator, which often causes people to overestimate personal risk compared to presenting risk information as an equivalent ratio with a larger numerator and denominator. 


\section{References}

Alibali, M. W., \& Sidney, P. G. (2015). Variability in the natural number bias: who, when, how, and why. Learning and Instruction, 37, 56-61. https://doi.org/10.1016/j.olearninstruc.2015.01.003

Alonso-Diaz, S., Cantlon, J. F., \& Piantadosi, S. T. (2019, July). Intrinsic whole number bias in an indigenous population [Poster presentation]. Cognitive Science Society, Montreal, Quebec, Canada.

Ashcraft, M. H. (2002). Mathematics anxiety: Personal, educational, and cognitive consequences. Current Directions in Psychological Science, 11(5), 181-185. https://doi.org/10.1111/1467-8721.00196

Ashcraft, M. H., \& Kirk, E. P. (2001). The relationships among working memory, math anxiety, and performance. Journal of Experimental Psychology: General, 130, 224-237. https://doi.org/10.1037//0096-3445.130.2.224

Begolli, K. N., Booth, J. L., Holmes, C. A., \& Newcombe, N. S. (2020). How many apples make a quarter? The challenge of discrete proportional formats. Journal of Experimental Child Psychology, 192, 1-20. https://doi.org/10.1016/j.jecp.2019.104774

Bonner, C., Trevena, L. J., Gaissmaier, W., Han, P. K. J., Okan, Y., Ozanne, E., Peters, E., Timmermans, D., \& Zikmund-Fisher, B. J. (2021). Current best practice for presenting probabilities in patient decision aids: Fundamental principles. Medical Decision Making. Advance online publication. https://doi.org/10.1177/0272989X21996328

Bonato, M., Fabbri, S., Umiltà, C., \& Zorzi, M. (2007). The mental representation of numerical fractions: Real or integer?. Journal of Experimental Psychology: Human Perception and Performance, 33, 1410-1419. https://doi.org/10.1037/0096-1523.33.6.1410

Bourdin, D., Engin, A., \& Vetschera, R. (2021). Is there more than one ratio bias? If so, why? Journal of Behavioral Decision Making, 1-16. https://doi.org/10.1002/bdm.2263

Boyer, T. W., Levine, S. C., Huttenlocher, J. (2008). Development of proportional reasoning: Where young children go wrong. Developmental Psychology, 44(5), 1478-1490. https://doi.org/10.1037/a0013110

Brainerd, C. J., \& Gordon, L. L. (1994). Development of verbatim and gist memory for numbers. Developmental Psychology, 30(2), 163-177. https://doi.org/10.1037/0012-1649.30.2.163

Braithwaite, D. W., \& Siegler, R. S. (2018). Children learn spurious associations in their math textbooks: Examples from fraction arithmetic. Journal of Experimental Psychology: Learning, Memory, and Cognition, 44(11), 1765-1777.

Braithwaite, D. W., \& Siegler, R. S. (2018). Developmental changes in the whole number bias. Developmental Science, 21(2), 1-13. https://doi.org/10.1111/desc.12541

Bustamante, A. S., Schlesinger, M., Begolli, K. N., Golinkoff, R. M., Shahidi, N., Zonji, S., Riesen, C., Evan, N., \& Hirsh-Pasek, K. (2020). More than just a game: Transforming social interaction and STEM play with Parkopolis. Developmental Psychology, 56(6), 1041-1056. https://doi.org/10.1037/dev0000923

Cacioppo, J. (2007). Psychology is a hub science. Observer, 20(8). https://www.psychologicalscience.org/observer/psychology-is-a-hub-science

Campbell, J. I. D. (2005). The Handbook of Mathematical Cognition. Psychology Press.

Carraher, T. N., Carraher, D. W., \& Schliemann, A. D. (1985). Mathematics in the streets and in schools. British Journal of Developmental Psychology, 3(1), 21-29. https://doi.org/10.1111/j.2044-835X.1985.tb00951.x

Common Core State Standards Initiative (CCSSO). (2010). Grade 1 - geometry - reason with shapes and their attributes - 3. http://www.corestandards.org/Math/Content/1/G/A/3/ 


\section{LEVERAGING MATH COGNITION}

Common Core State Standards in Mathematics (CCSSM). (n.d.). Progressions Documents for the Common Core Math Standards. http://ime.math.arizona.edu/progressions/\#about

Chan, J. Y-C., \& Mazzocco, M. M. M. (2016). Competing features influence children's attention to number. Journal of Experimental Child Psychology, 156, 62-81. https://doi.org/10.1016/j.jecp.2016.11.008

Chi, M. T. H., Feltovich, P. J., \& Glaser, R. (1981). Categorization and representation of physics problems by experts and novices. Cognitive Science, 5(2), 121-152. https://doi.org/10.1207/s15516709cog0502 2

Choi, S. S., Taber, J. M., Thompson, C. A., \& Sidney, P. G. (2020). Math anxiety, but not induced stress, is associated with objective numeracy. Journal of Experimental Psychology: Applied. Advance online publication. https://doi.org/10.1037/xap0000268

Clarke, S., \& Beck, J. (2021). The number sense represents (rational) numbers. Behavioral \& Brain Sciences.

Cokely, E. T., Galesic, M., Schulz, E., Ghazal, S., \& Garcia-Retamero, R. (2012). Measuring risk literacy: The Berlin numeracy test. Judgment and Decision Making, 7(1), 25-47.

Confrey, J., Maloney, A. P., \& Corley, A. K. (2014). Learning trajectories: a framework for connecting standards with curriculum. ZDM, 46, 719-733. https://doi.org/10.1007/s11858-014-0598-7

Conradt, S. (2016). Why no one wanted A\&W's third-pound burger. Retrieved from: https://www.mentalfloss.com/article/76144/why-no-one-wanted-aws-third-pound-burger

Cuite, C. L., Weinstein, N. D., Emmons, K., \& Colditz, G. (2008). A test of numeric formats for communicating risk probabilities. Medical Decision Making, 28(3), 377-384. https://doi.org/10.1177/0272989X08315246

Dehaene, S. (2011). The Number Sense ( $2^{\text {nd }}$ ed.). New York, NY: Oxford University Press.

Dehaene, S., Dehaene-Lambertz, G., \& Cohen, L. (1998). Abstract representations of numbers in the animal and human brain. Trends in Neurosciences, 21(8), 355-361. https://doi.org/10.1016/S0166-2336(98)01263-6

Dehaene, S., \& Mehler, J. (1992). Cross-linguistic regularities in the frequency of number words. Cognition, 43(1), 1-29. https://doi.org/10.1016/0010-0277(92)90030-L

Denes-Raj, V., \& Epstein, S. (1994). Conflict between intuitive and rational processing: When people behave against their better judgment. Journal of Personality and Social Psychology, 66(5), 819-829. https://doi.org/10.1037/0022-3514.66.5.819

DeWolf, M., \& Vosniadou, S. (2015). The representation of fraction magnitudes and the whole number bias reconsidered. Learning and Instruction, 37, 39-49. https://doi.org/10.1016/j.learninstruc.2014.07.002

Eason, S. H., \& Ramani, G. B. (2020). Parent-child math talk about fractions during formal learning and guided play activities. Child Development, 91(2), 546-562. https://doi.org/10.1111/cdev.13199

Fagerlin, A., Zikmund-Fisher, B. J., Ubel, P. A., Jankovic, A., Derry, H. A., \& Smith, D. M. (2007). Measuring numeracy without a mathematics test: development of the subjective numeracy scale. Medical Decision Making, 27, 672-680. https://doi.org/10.1177/0272989X07304449

Fazio, L. K., Bailey, D. H., Thompson, C. A., \& Siegler, R. S. (2014). Relations of different types of numerical magnitude representations to each other and to mathematics achievement. Journal of Experimental Child Psychology, 123, 53-72. https://doi.org/10.1016/j.jecp.2014.01.013

Fazio, L. K., DeWolf, M., \& Siegler, R. S. (2017). Strategy use and strategy choice in fraction 


\section{LEVERAGING MATH COGNITION}

magnitude comparison. Journal of Experimental Psychology, Learning, Memory, and Cognition, 42, 1-16. https://doi.org/10.1037/xlm0000153

Feigenson, L., Dehaene, S., \& Spelke, E. (2004). Core systems of number. Trends in Cognitive Sciences, 8(7), 307-314. https://doi.org/10.1016/j.tics.2004.05.002

Fitzsimmons, C. J., \& Thompson, C. A. (2021). Is there a whole-number bias in children's and adults' monitoring of magnitude estimation? The differential role of familiarity in whole-number and fraction estimates and confidence judgments [Manuscript in preparation]. Department of Psychology, Kent State University.

Fitzsimmons, C. J., Thompson, C. A., \& Sidney, P. G. (2020a). Confident or familiar? The role of familiarity ratings in adults' confidence judgments when estimating fraction magnitudes. Metacognition and Learning, 15, 215-231. https://doi.org/10.1007/s11409-020-09225-9

Fitzsimmons, C. J., Thompson, C. A., \& Sidney, P. G. (2020b). Do adults treat equivalent fractions equally? Adults' strategies and errors during fraction reasoning. Journal of Experimental Psychology: Learning, Memory, and Cognition, 46(11), 2049-2074. https://doi.org/10.1037/xIm0000839

Furlong, E. E., \& Opfer, J. E. (2009). Cognitive constraints on how economic rewards affect cooperation. Psychological Science, 20(1). https://doi.org/10.1111/j.1467-9280.2008.02244.x

Geary, D. C., Scofield, J. E., Hoard, M. K., \& Nugent, L. (2020). Boys' advantage on the fractions number line is mediated by visuospatial attention: Evidence for a parietal-spatial contribution to number line learning. Developmental Science, 1-19. https://doi.org/10.1111/desc. 13063

Gentner, D. (1983). Structure-mapping: A theoretical framework for analogy. Cognitive Science, 7(2), 155-170. https://doi.org/10.1207/s15516709cog0702 _ 3

Gigerenzer, G., \& Hoffrage, U. (1995). How to improve Bayesian reasoning without instruction: Frequency formats. Psychological Review, 102(4), 684-704. https://doi.org/10.1037/0033-295X.102.4.684

Gómez, D. M., Jiménez, A., Bobadilla, R., Reyes, C., \& Dartnell, P. (2015). The effect of inhibitory control on general mathematics achievement and fraction comparison in middle school children. ZDM, 47(5), 801-811. https://doi.org/10.1007/s11858-015-0685-4

Griffin, S. A., Case, R., \& Siegler, R. S. (1994). Rightstart: Providing the central conceptual prerequisites for first formal learning of arithmetic to students at risk for school failure. In K. McGilly (Ed.), Classroom lessons: Integrating cognitive theory and classroom practice (pp. 25-49). The MIT Press.

Halberda, J., Ly, R., Wilmer, J. B., Naiman, D. Q., \& Germine, L. (2012). Number sense across the lifespan as revealed by a massive internet-based sample. Proceedings of the National Academy of Sciences of the United States of America, 109(28), 11116-11120. https://doi.org/10.1073/pnas.1200196109

Hall, K. L., Vogel, A. L., Huang, G. C., Serrano, K. J., Rice, E. L., Tsakraklides, S. P., \& Fiore, S. M. (2018). The science of team science: A review of the empirical evidence and research gaps on collaboration in science. American Psychologist, 73(4), 532-548. https://doi.org/10.1037/amp0000319

Hannula, M. H., Lepola, J., \& Lehtinen, E. (2010). Spontaneous focusing on numerosity as a domain-specific predictor of arithmetical skills. Journal of Experimental Child Psychology, 107(4), 394-406. https://doi.org/10.1016/j.jecp.2010.06.004 


\section{LEVERAGING MATH COGNITION}

Hunt, R.R. (2013). Precision in memory through distinctive processing. Current Directions in Psychological Science. 22(1):10-15. http://doi.org/10.1177/0963721412463228

Hutchison, J. E., Lyons, I. M., \& Ansari, D. (2019). More similar than different: Gender differences in children's basic numerical skills are the exception not the rule. Child Development, 90, e66-e79. https://doi.org/10.1111/cdev.13044

Jacob, S. N., Vallentin, D., \& Nieder, A. (2012). Relating magnitudes: The brain's code for proportions. Trends in Cognitive Sciences, 16(3), 157-166. https://doi.org/10.1016/j.tics.2012.02.002

Klein, W. M., Grenen, E. G., O’Connell, M., Blanch-Hartigan, D., Chou, W. Y. S., Hall, K. L., Taber, J. M., \& Vogel, A. L. (2017). Integrating knowledge across domains to advance the science of health behavior: Overcoming challenges and facilitating success. Translational Behavioral Medicine, 7(1), 98-105. https://doi.org/10.1007/s13142-016-0433-5

Koedinger, K. R. \& Nathan, M. (2004). The real story behind story problems: Effects of representations on quantitative reasoning. Journal of the Learning Sciences, 13(2), 129-164. https://doi.org/10.1207/s15327809jls1302 1

Lamon, S. J. (2020). Teaching fractions and ratios for understanding: Essential content knowledge and instructional strategies for teachers (4th ed.). Routledge.

Leibovich, T., Katzin, N., Harel, M., \& Henik, A. (2017). From 'sense of number' to 'sense of magnitude'-The role of continuous magnitudes in numerical cognition. Behavioral and Brain Sciences, 1-62.

Levine, S. C., Suriyakham, L. W., Rowe, M. L., Huttenlocher, J., \& Gunderson, E. A. (2010). What counts in the development of young children's number knowledge?. Developmental Psychology, 46(5), 1309-1319. https://doi.org/10.1037/a0019671

Lipkus, I. M. (2007). Numeric, verbal, and visual formats of conveying health risks: Suggested best practices and future recommendations. Medical Decision Making, 27(5), 696-713. https://doi.org/10.1177/0272989X07307271

Lipkus, I. M., \& Peters, E. (2010). Understanding the role of numeracy in health: Proposed theoretical framework and practical insights. Health Education \& Behavior, 36(6),1065-1081. https://doi.org/10.1177/1090198109341533

$\mathrm{Ma}, \mathrm{X}$. (1999). A meta-analysis of the relationship between anxiety toward mathematics and achievement in mathematics. Journal for Research in Mathematics Education, 30(5), 520-540. https://doi.org/10.2307/749772

Marcus, G. F., Vijayan, S., Rao, S. B., \& Vishton, P. M. (1999). Rule learning by seven-month-old infants. Science, 283(5398), 77-80. https://doi.org/10.1126/science.283.5398.77

Markman, A., \& Gentner, D. (2000). Structure mapping in the comparison process. The American Journal of Psychology, 113(4), 501-538. http://doi.org/10.2307/1423470

Matthews, P. G., Lewis, M. R., Hubbard, E. M. (2015). Individual differences in nonsymbolic ratio processing predict symbolic math performance. Psychological Science, 1-12. https://doi.org/10.1177/0956797615617799

McCrink, K., \& Wynn, K. (2007). Ratio abstraction by 6-month-old infants. Psychological Science, 18(8), 740-745. https://doi.org/10.1111/j.1467-9280.2007.01969.x

McNeil, N. M. (2008). Limitations to teaching children $2+2=4$ : Typical arithmetic problems can hinder learning of mathematical equivalence. Child Development, 79(5), 1524-1537. https://doi.org/10.1111/j.1467-8624.2008.01203.x 


\section{LEVERAGING MATH COGNITION}

McNeil, N. M., Fyfe, E. R., \& Dunwiddie, A. E. (2015). Arithmetic practice can be modified to promote understanding of mathematical equivalence. Journal of Educational Psychology, 107(2), 423-436. https://doi.org/10.1037/a0037687

Mielicki, M., Fitzsimmons, C. J., Schiller, L., Scheibe, D. A., Taber, J. M., Sidney, P. G., Matthews, P., Waters, E. A., Coifman, K., \& Thompson, C. A. (2021). Adults' health-related problem solving is facilitated by number lines, but not risk ladders and icon arrays. Manuscript under review.

Mielicki, M., Fitzsimmons, C., Woodbury, H., Marshal, H., Zhang, D., Rivera, F., \& Thompson, C. A. (2021). Effects of figural and numerical presentation formats on growing pattern performance. Journal of Numerical Cognition. 7, 125-155. https://doi.org/10.5964/jnc.6945

Mielicki, M. K., Wilkey, E. D., Scheibe, D., Fitzsimmons, C. J., Sidney, P. G., Soltanlou, M., Starling-Alves, I., Coolen, I., Ansari, D., \& Thompson, C. A. (2021). Task features change the relation between math anxiety and number line estimation performance with rational numbers: A large-scale online study. Manuscript under review.

Moss, J., \& Case, R. (1999). Developing children's understanding of the rational numbers: A new model and an experimental curriculum. Journal for Research in Mathematics Education, 30(2), 122-147. https://doi.org/10.2307/749607

Nelson, W., Reyna, V. F., Fagerlin, A., Lipkus, I., \& Peters, E. (2008). Clinical implications of numeracy: theory and practice. Annals of Behavioral Medicine, 35(3), 261-274. https://doi.org/10.1007/s12160-008-9037-8

Nelson, W., Reyna, V. F., Fagerlin, A., Lipkus, I., \& Peters, E. (2008). Clinical implications of numeracy: Theory and practice. Annals of Behavioral Medicine, 35(3), 261-274. https://doi.org/10.1007/s12160-008-9037-8

Netburn, D. (2020, March 5). The flu has killed far more people than coronavirus. So why all the frenzy about COVID-19? Los Angeles Times.

https://www.latimes.com/science/story/2020-03-05/flu-killed-more-people-coronavirus-co vid-19

Newcombe, N., Levine, S. C., \& Mix, K. S. (2015). Thinking about quantity: The intertwined development of spatial and numerical cognition. Cognitive Science, 6(6), 491-505. https://doi.org/10.1002/wcs.1369

$\mathrm{Ni}$, Y., \& Zhou, Y. D. (2005). Teaching and learning fraction and rational numbers: The origins and implications of whole number bias. Educational Psychologist, 40(1), 27-52. https://doi.org/10.1207/s15326985ep4001 3

National Research Council. (2015). Enhancing the Effectiveness of Team Science. Committee on the Science of Team Science, N.J. Cooke and M.L. Hilton, Editors. Board on Behavioral, Cognitive, and Sensory Sciences, Division of Behavioral and Social Sciences and Education. Washington, DC: The National Academies Press.

NMAP (2008). Foundations for success: Report of the National Mathematics Advisory Board Panel: U.S. Government Printing Office.

Norton, A., \& Nurnberger-Haag, J. (2018). Bridging frameworks for understanding numerical cognition. Journal of Numerical Cognition, 4(1), 1-8. https://doi.org/10.5964/jnc.v4i1.160

Núñez-Peña, M. I., Guilera, G., Suárez-Pellicioni, M. (2014). The single-item math anxiety scale: An alternative way of measuring mathematical anxiety. Journal of Psychoeducational Assessment, 32(4), 306-317. https://doi.org/10.1177/0734282913508528

Obersteiner, A., Van Dooren, W., Van Hoof, J., \& Verschaffel, L. (2013). The natural number bias and magnitude representation in fraction comparison by expert mathematicians. Learning and Instruction, 28, 64-72. https://doi.org/10.1016/i.learninstruc.2013.05.003 


\section{LEVERAGING MATH COGNITION}

Obersteiner, A., Alibali, M. W., \& Marupudi, V. (2020). Complex fraction comparisons and the natural number bias: The role of benchmarks. Learning and Instruction, 67, PAGES? https://doi.org/10.1016/j.learninstruc.2020.101307

Opfer, J. E., \& DeVries, J. M. (2008). Representational change and magnitude estimation: Why young children can make more accurate salary comparisons than adults. Cognition, 108(3), 843-849. https://doi.org/10.1016/j.cognition.2008.05.003

Opfer, J. E., Thompson, C. A. \& Furlong, E. E. (2010). Early development of spatial-numeric associations: Evidence from spatial and quantitative performance of preschoolers.

Developmental Science, 13(5), 761-771. https://doi.org/10.1111/j.1467-7687.2009.00934.x

Organization for Economic Cooperation and Development. (2016). Skill matter: Further results from the survey of adult skills, OECD Skills Series, OECD Publishing, Paris, France. https://doi.org/10.1787/23078731

Organization for Economic Cooperation and Development (OECD). (2018). Programme for International Student Assessment. https://www.oecd.org/pisal

Paik, J. H., \& Mix, K. S. (2003). U.S. and Korean children's comprehension of fraction names: A reexamination of cross-national differences. Child Development, 74(1), 144-154. https://doi.org/10.1111/1467-8624.t01-1-00526

Peters, E. (2020). Innumeracy in the Wild: Misunderstanding and misusing numbers. New York, NY: Oxford University Press.

Peters, E., \& Bjalkebring, P. (2015). Multiple numeric competencies: When a number is not just a number. Journal of Personality and Social Psychology, 108(5), 802-822. https://doi.org/10.1037/pspp0000019

Peters, E., Tompkins, M. K., Knoll, M. A. Z., Ardoin, S. P., Shoots-Reinhard, B., \& Meara, A. S. (2019). Despite high objective numeracy, lower numeric confidence relates to worse financial and medical outcomes. Proceedings of the National Academy of Sciences of the United States of America, 116(39), 19386-19391. https://doi.org/10.1073/pnas.1903126116

Peters, E., Västfjäll, D., Slov, P., Mertz, C. K., Mazzocco, K., \& Dickert, S. (2006). Numeracy and decision making. Psychological Science, 17(5), 407-413. https://doi.org/10.1111/j.1467-9280.2006.01720.x

Pica, P., Lemur, C., Izard, V., \& Dehaene, S. (2004). Exact and approximate arithmetic in an Amazonian indigene group. Science, 306(5695), 499-503. https://doi.org/10.1126/science.1102085

Pighin, S., Savadori, L., Barilli, E., Cremonesi, L., Ferrari, M., \& Bonnefon, J-F. (2011). The 1 -in-X effect on the subjective assessment of medical probabilities. Medical Decision Making, 31(5), 721-729. https://doi.org/10.1177/0272989X11403490

Pruden, S. M., Levine, S. C., \& Huttenlocher, J. (2011). Children's spatial thinking: Does talk about the spatial world matter? Developmental Science, 14(6), 1417-1430. https://doi.org/10.1111/i.1467-7687.2011.01088.x

Ramani, G. B., \& Siegler, R. S. (2008). Promoting broad and stable improvements in low-income children's numerical knowledge through playing number board games. Child Development, 79(2), 375-394. https://doi.org/10.1111/j.1467-8624.2007.01131.x

Ramani, G. B., \& Siegler, R. S. (2009). Playing linear number board games-but not circular ones-improves low-income preschoolers' numerical understanding. Journal of Educational Psychology, 101(3), 545-560. https://doi.org/10.1037/a0014239

Reinhold, F., Obersteiner, A., Hoch, S., Hofer, S. I., \& Reiss, K. (2020). The interplay between 


\section{LEVERAGING MATH COGNITION}

the natural number bias and fraction magnitude processing in low-achieving students.

Frontiers in Education, 5, 1-13. https://doi.org/10.3389/feduc.2020.00029

Reyna, V. F. (1991). Class inclusion, the conjunction fallacy, and other cognitive illusions. Developmental Review, 11(4), 317-336. https://doi.org/10.1016/0273-2297(91)90017-I

Reyna, V. F. (2008). A theory of medical decision making and health: Fuzzy trace theory. Medical Decision Making, 28(6), 850-865. https://doi.org/10.1177/0272989X08327066

Reyna, V. F. (2012). A new intuitionism: Meaning, memory, and development in fuzzy-trace theory. Judgment and Decision Making, 7(3), 332-359.

Reyna, V. F., \& Brainerd, C. J. (1991). Fuzzy-trace theory and children's acquisition of mathematical and specific concepts. Learning and Individual Differences, 3(1), 27-59. https://doi.org/10.1016/1041-6080(91)90003-J

Reyna, V. F., \& Brainerd, C. J. (2007). The importance of mathematics in health and human judgment: Numeracy, risk communication, and medical decision making. Learning and Individual Differences, 17(2), 147-159.

Reyna, V. F., \& Brainerd, C. J. (2008). Numeracy, ratio bias, and denominator neglect in judgments of risk and probability. Learning and Individual Differences, 18(1), 89-107. https://doi.org/10.1016/j.lindif.2007.03.011

Rittle-Johnson, B. (2017). Developing mathematics knowledge. Child Development Perspectives, 11(3), 184-190. https://doi.org/10.1111/cdep.12229

Rugani, R., McCrink, K., De Hevia M.D, Vallortigara, G. and Regolin, L. (2016). Ratio calculation over discrete magnitudes by newly hatched domestic chicks (Gallus gallus). Scientific Reports, 6, 30114.

Rivers, M. L., Fitzsimmons, C. J., Fisk, S. R., Dunlosky, J., \& Thompson, C. A. (2020). Gender differences in confidence during number-line estimation. Metacognition and Learning. https://doi.org/10.1007/s11409-020-09243-7

Saffran, J. R., Aslin, R. N., \& Newport, E. L. (1996). Statistical learning by 8-month-old infants. Science, 274(5294), 1926-1928. https://doi.org/10.1126/science.274.5294.1926

Scheibe, D. A., Fitzsimmons, C. J., Mielicki, M. K., Taber, J. M., Sidney, P. G., Coifman, K. \& Thompson, C.A. (2021). When it's healthy to be confident: What factors predict adults' metacognitive judgments on COVID-related math problems before and after their engagement with an educational intervention? [Manuscript submitted for publication]. Department of Psychology, Kent State University.

Scheideler, J. K., Taber, J. M., Ferrer, R. A., Grenen, E. G., \& Klein, W. M. P. (2017). Heart disease versus cancer: Understanding perceptions of population prevalence and personal risk. Journal of Behavioral Medicine, 40(5), 839-845. https://doi.org/10.1007/s10865-017-9860-0

Schiller, L. K. (2020). Recharging rational number understanding (Publication No. 27671317) [Doctoral dissertation, Columbia University]. ProQuest Dissertations and Theses Global.

Schiller, L. K., Siegler, R. S., \& Thompson, C. A. (2022). Monster math race: Chasing integrated number sense [Manuscript in preparation]. Psychological Sciences, Kent State University.

Schneider, M., \& Siegler, R. S. (2010). Representations of the magnitudes of fractions. Journal of Experimental Psychology: Human Perception and Performance, 36(5), 1227-1238. https://doi.org/10.1037/a0018170

Sidney, P. G., Shirah, J. F., Zahrn, L., \& Thompson, C. A. (2022). Diagrams support spontaneous transfer across whole number and fraction concepts. Contemporary Educational Psychology. 


\section{LEVERAGING MATH COGNITION}

Sidney, P. G., Thalluri, R., Buerke, M. L., \& Thompson, C. A. (2019). Who uses more

strategies? Linking mathematics anxiety to adults' strategy variability and performance on fraction magnitude tasks. Thinking and Reasoning, 25(1), 94-131.

https://doi.org/10.1080/13546783.2018.1475303

Sidney, P. G., \& Thompson, C. A. (2019). Implicit analogies in learning: Supporting transfer by warming up. Current Directions in Psychological Science, 28(6), 619-625. https://doi.org/10.1177/0963721419870801

Sidney, P. G., Thompson, C. A., Fitzsimmons, C., \& Taber, J. M (2021). Children's and adults'

math attitudes are differentiated by number type. The Journal of Experimental Education, 1-32. https://doi.org/10.1080/00220973.2019.1653815

Sidney, P. G., Thompson, C. A., Matthews, P. G., \& Hubbard, E. M. (2017). From continuous magnitudes to symbolic numbers: The centrality of ratio. Behavioral and Brain Sciences, 40, Article e190. https://doi.org/10.1017/S0140525X16002284

Sidney, P., Thompson, C. A., \& Opfer, J. E. (2019). Development of fraction understanding. In J. Dunlosky \& K. Rawson (Eds.), Cambridge University Handbook on Cognition and Education (pp. 148-182). Cambridge University Press.

Sidney, P., Thompson, C. A., \& Rivera, F. (2019). Number lines, but not area models, support children's accuracy and conceptual models of fraction division. Contemporary Educational Psychology, 58, 288-298. https://doi.org/10.1016/j.cedpsych.2019.03.011

Siegler, R. S. (1994). Cognitive variability: A key to understanding cognitive development. Current Directions in Psychological Science, 3(1), 1-5. https://doi.org/10.1111/1467-8721.ep10769817

Siegler, R. S. (1996). Emerging minds: The process of change in children's thinking. New York, NY: Oxford University Press.

Siegler, R. S. (2016). Magnitude knowledge: The common core of numerical development. Developmental Science, 19, 341-361. https://doi.org/10.1111/desc.12395

Siegler, R., Carpenter, T., Fennell, F., Geary, D., Lewis, J., Okamoto, Y., Thompson, L., \& Wray, J. (2010). Developing effective fractions instruction: A practice guide (NCEE \#2010-009). Washington, DC: National Center for Education Evaluation and Regional Assistance, Institute of Education Sciences, U.S. Department of Education.

Siegler, R. S., \& Opfer, J. (2003). The development of numerical estimation: Evidence for multiple representations of numerical quantity. Psychological Science, 14, 237-243. https://doi.org/10.1111/1467-9280.02438

Siegler, R. S., \& Ramani, G. B. (2008). Playing linear numerical board games promotes low-income children's numerical development. Developmental Science, 11(5), 655-661. https://doi.org/10.1111/j.1467-7687.2008.00714.x

Siegler, R. S., \& Thompson, C. A. (2014). Numerical landmarks are useful--except when they're not. Journal of Experimental Child Psychology, 120, 39-58.

https://doi.org/10.1016/j.jecp.2013.11.014

Siegler, R. S., Thompson, C. A., \& Opfer, J. E. (2009). The logarithmic-to-linear shift: one learning sequence, many tasks, many time scales. Mind, Brain, and Education, 3(3), 143-150. https://doi.org/10.1111/j.1751-228X.2009.01064.x 


\section{LEVERAGING MATH COGNITION}

Siegler, R. S., Thompson, C. A., \& Schneider, M. (2011). An integrated theory of whole number and fractions development. Cognitive Psychology, 62, 273-296.

https://doi.org/10.1016/j.cogpsych.2011.03.001

Siegler, R. S., Duncan, G. J., Davis-Kean, P. E., Duckworth, K., Claessens, A., Engel, M., Susperreguy, M. I., \& Chen, M. (2012). Early predictors of high school mathematics achievement. Psychological Science, 23(7), 691-697.

https://doi.org/10.1177/0956797612440101

Siegler, R. S., Fazio, L. K., Bailey, D. H., \& Zhou, X. (2013). Fractions: The new frontier for theories of numerical development. Trends in Cognitive Sciences, 17(1), 13-19. https://doi.org/10.1016/i.tics.2012.11.004

Sirota, M., Juanchich, M., \& Bonnefon, J.-F. (2018). "1-in-X" bias: "1-in-X" format causes overestimation of health-related risks. Journal of Experimental Psychology, Applied, 24(4), 431-439. https://doi.org/10.1037/xap0000190

Sloman, S. A., Over, D., Slovak, L., \& Stibel, J. M. (2003). Frequency illusions and other fallacies. Organizational Behavior and Human Decision Processes, 91(2), 296-309. https://doi.org/10.1016/S0749-5978(03)00021-9

Sobkow, A., Fulawka, K., Tomczak, P., Zjawiony, P., \& Traczyk, J. (2019). Does mental number line training work? The effects of cognitive training on real-life mathematics, numeracy, and decision making. Journal of Experimental Psychology: Applied, 25(3), 372-385. https://doi.org/10.1037/xap0000207

Spelke, E. S., \& Kinzler, K. D. (2007). Core knowledge. Developmental Science, 10(1), 89-96. https://doi.org/10.1111/j.1467-7687.2007.00569.x

Steffe, L. P. \& Olive, J. (2009). Children's fractional knowledge. New York, NY: Springer.

Stone, E. R., Sieck, W. R., Bull, B. E., Yates, J. F., Parks, S. C., \& Rush, C. J. (2003). Foreground:background salience: Explaining the effects of graphical displays on risk avoidance. Organizational Behavior and Human Decision Processes, 90(1), 19-36. https://doi.org/10.1016/S0749-5978(03)00003-7

Thompson, C. A., \& Opfer, J. E. (2008). Costs and benefits of representational change: Effectsof context on age and sex differences in symbolic magnitude estimation. Journal of Experimental Child Psychology, 101(1), 20-51. https://doi.org/10.1016/j.jecp.2008.02.003

Thompson, C. A., \& Opfer, J. E. (2016). Learning linear spatial-numeric associations improves accuracy of memory for numbers. Frontiers in Psychology, 7. https://doi.org/10.3389/fpsyg.2016.00024

Thompson, C. A., \& Siegler, R. S. (2010). Linear numerical-magnitude representations aid children's memory for numbers. Psychological Science, 21(9), 1274-1281. https://doi.org/10.1177/0956797610378309

Thompson, C. A., Taber, J. M., Fitzsimmons, C. \& Sidney, P. (2021). Math predictors of numeric health and non-health decision-making problems.. Journal of Numerical Cognition, 7(2), 221-239.https://doi.org/10.5964/jnc.6545

Thompson, C. A., Taber, J. M., Sidney, P. G., Fitzsimmons, C. J., Mielicki, M. K., Matthews, P. G., Schemmel, E. A., Simonovic, N., Foust, J. L., Aurora, P., Disabato, D. J., Seah, T. H. S., \& Coifman, K. G. (in press). Math matters during a pandemic: A novel, brief educational intervention combats whole number bias to improve health decision-making 


\section{LEVERAGING MATH COGNITION}

and predicts COVID-19 risk perceptions and worry across 10 days. Journal of Experimental Psychology: Applied.

Thompson, C. A., Taber, J. M., Sidney, P., \& Coifman, K. (2020). Math misconceptions may lead people to underestimate the true threat of COVID-19. The Conversation.

https://theconversation.com/math-misconceptions-may-lead-people-to-underestimate-the -true-threat-ofcoivd-19-134520

Trevena, L. J., Bonner, C., Okan, Y., Peters, E., Gaissmaier, W., Han, P. K. J., Ozanne, E., Timmermans, D., \& Zikmund-Fisher, B. J. (2021). Current challenges when using numbers in patient decision aids: Advanced concepts. Medical Decision Making. Advance online publication. https://doi.org/10.1177/0272989X21996342

Vamvakoussi, X., \& Vosniadou, S. (2004). Understanding the structure of the set of rational numbers: A conceptual change approach. Learning and Instruction, 14, 453-467. https://doi.org/10.1016/j.learninstruc.2004.06.013

Vamvakoussi, X. \& Vosniadou, S. (2010). How many decimals are there between two fractions? Aspects of secondary school students' understanding of rational numbers and their notation. Cognition and Instruction, 28(2), 181-209. https://doi.org/10.1080/07370001003676603

Van Hoof, J., Verschaffel, L., \& Van Dooren, W. (2015). In search for the natural number bias in secondary school students' interpretation of the effect of arithmetical operations. Learning and Instruction, 37, 30-38.

Van Hoof, J., Verschaffel, L., De Neys, W., \& Van Dooren, W. (2020). Intuitive errors in learners' fraction understanding: A dual-process perspective on the natural number bias. Memory and Cognition, 48, 1171-1180. https://doi.org/10.3758/s13421-020-01045-1

Wall, J. E., Thompson, C. A., \& Morris, B. (2015). Confidence judgments and eye fixations reveal adults' fractions knowledge. Proceedings of the $37^{\text {th }}$ Annual Conference of the Cognitive Science Society.

Waters, E. A., Fagerlin, A., \& Zikmund-Fisher, B. J. (2016). Overcoming the many pitfalls of communicating risk. In M. A. Diefenbach, S. Miller-Halegoua, \& D. J. Bowen (Eds.), Handbook of Health Decision Science, pp. 265-277. New York, NY: Springer. https://doi.org/10.1007/978-1-4939-3486-7 19

Waters, E. A., Biddle, C., Kaphingst, K. A., Schofield, E., Kiviniemi, M. T., Orom, H., Li, Y., \& Hay, J. L. (2018). Examining the interrelations among objective and subjective health literacy and numeracy and their associations with health knowledge. Journal of general internal medicine, 33(11), 1945-1953. https://doi.org/10.1007/s11606-018-4624-2

Waters, E. A., Maki, J., Liu, Y., Ackermann, N., Carter, C. R., Dart, H., Bowen, D. J., Cameron, L. D., \& Colditz, G. A. (2021). Risk ladder, table, or bulleted list? Identifying formats that effectively communicate personalized risk and risk reduction information for multiple diseases. Medical decision making: An international journal of the Society for Medical Decision Making, 41(1), 74-88.

Waters, E. A., Foust, J. L., Scherer, L. D., McQueen, A., \& Taber, J. M. (2021). Adherence of internet-based cancer risk assessment tools to best practices in risk communication: Content analysis. Journal of Medical Internet Research, 23(1): e23318. https://doi.org/10.2196/23318

Weller J. A., Dieckmann N.F., Tusler M., Mertz C.K., Burns W.J., Peters E. (2013).

Development and testing of an abbreviated numeracy scale: A Rasch analysis approach. Journal of Behavioral Decision Making, 26, 198-212. $\quad$ https://doi.org/10.1002/bdm.1751 


\section{LEVERAGING MATH COGNITION}

Wolfe, C. R., \& Reyna, V. F. (2009). Semantic coherence and fallacies in estimating joint probabilities. Behavioral Decision Making, 23(2), 203-223. https://doi.org/10.1002/bdm.650

Woodbury, L., Fitzsimmons, C.J., Taber, J.M., Schiller, L., \& Thompson, C. A. (2021). Impact of presentation format on health risk estimates, strategy reports, and confidence judgment [Manuscript submitted for publication]. Department of Psychology, Kent State University

Xu, F., \& Spelke, E. S. (2000). Large number discrimination in 6-month-old infants. Cognition, 74, B1-B11. https://doi.org/10.1016/S0010-0277(99)00066-9

Yu, S., Kim, D., Mielicki, M. K., Fitzsimmons, C., Thompson, C. A., \& Opfer, J. E. (2020). From integers to fractions: Developing a coherent understanding of proportional magnitude. In S. Denison, M. Mack, Y. Xu, and B.C. Armstrong (Eds.) Proceedings of the 42nd annual conference of the Cognitive Science Society. Cognitive Science Society.

Yu, S., Kim, D., Fitzsimmons, C. J., Mielicki, M. K., Thompson, C. A., \& Opfer, J., (2021). From integers to fractions: Developing a coherent understanding of proportional magnitude [Manuscript in preparation]. Department of Psychology, The Ohio State University.

Zikmund-Fisher, B. J. (2011). Time to retire the 1-in-X risk format. Medical Decision Making, 31(5), 703-704. https://doi.org/10.1177/0272989X11418238

Zikmund-Fisher, B. J. (2013). Continued use of 1-in-X risk communications is a systemic problem. Medical Decision Making, 34(4), 412-413. https://doi.org/10.1177/0272989X13516198

Zikmund-Fisher, B. J. (2013). The right tool is what they need, not what we have: A taxonomy of appropriate levels of precision in patient risk communication. Medical Care Research and Review. 70, 37S-49S. https://doi.org/10.1177/1077558712458541 